Florida International University

FIU Digital Commons

3-28-2003

\title{
Assessment of monitored natural attenuation as a remedial option at Savannah River site's sanitary landfill using the biochlor model
}

Srinivasa Rao Gadiparthi

Florida International University

Follow this and additional works at: https://digitalcommons.fiu.edu/etd

Part of the Civil and Environmental Engineering Commons

\section{Recommended Citation}

Gadiparthi, Srinivasa Rao, "Assessment of monitored natural attenuation as a remedial option at Savannah River site's sanitary landfill using the biochlor model" (2003). FIU Electronic Theses and Dissertations. 3430.

https://digitalcommons.fiu.edu/etd/3430

This work is brought to you for free and open access by the University Graduate School at FIU Digital Commons. It has been accepted for inclusion in FIU Electronic Theses and Dissertations by an authorized administrator of FIU Digital Commons. For more information, please contact dcc@fiu.edu. 


\title{
FLORIDA INTERNATIONAL UNIVERSITY \\ Miami, Florida
}

\begin{abstract}
ASSESSMENT OF MONITORED NATURAL ATTENUATION AS A REMEDIAL
OPTION AT SAVANNAH RIVER SITE'S SANITARY LANDFILL USING THE

BIOCHLOR MODEL
\end{abstract}

A thesis submitted in partial fulfillment of the

requirements for the degree of

MASTER OF SCIENCE

in

CIVIL ENGINEERING

by

Srinivasa Rao Gadiparthi

2003 
To: Dean Vish Prasad

College of Engineering

This thesis, written by Srinivasa Rao Gadiparthi, and entitled Assessment of Monitored Natural Attenuation as a Remedial Option at Savannah River Site's Sanitary Landfill Using the BIOCHLOR Model, having been approved in respect to style and intellectual content, is referred to you for judgment.

We have read this thesis and recommend that it be approved.

Ali Ebadian

Shonali Laha

Marshall Allen

Berrın Tansel, Major Professor

Date of Defense: March 28, 2003

The thesis of Srinivasa Rao Gadiparthi is approved. 


\section{DEDICATION}

This thesis is dedicated to all those whose support, guidance, and encouragement have enabled me to accomplish this work. 


\section{ACKNOWLEDGMENTS}

I am greatly indebted to my major professor, Dr. Berrin Tansel, for providing a golden opportunity to work on this subject. I thank Dr. Berrin Tansel for her support, wisdom, guidance, encouragement, understanding and patience throughout the duration of my graduate studies at FIU.

I would like to express my deepest gratitude to my mentor and committee member, Mr. Marshall Allen from HCET-FIU for his support and guidance.

Word of thanks must go to my committee member Dr. Shonali Laha, for her suggestions, and valuable cooperation.

The research for this thesis was funded by HCET-FIU. The contents of this thesis do not necessarily reflect the views and policies of HCET-FIU. 


\section{ABSTRACT OF THE THESIS \\ ASSESSMENT OF MONITORED NATURAL ATTENUATION AS A REMEDIAL OPTION AT SAVANNAH RIVER SITE'S SANITARY LANDFILL USING THE \\ BIOCHLOR MODEL \\ by \\ Srinivasa Rao Gadiparthi}

Florida International University, 2003

Miami, Florida

Professor Berrin Tansel, Major Professor

The purpose of this research was to assess the feasibility of monitored natural attenuation (MNA) as a remedial option at Savannah River Site's (SRS) Sanitary Landfill using the BIOCHLOR screening model.

Phase I Environmental Site Assessment (ESA) results are used to identify the nature, quantity and the sources of contaminants, and Phase II ESA results are used to identify hydrogeologic and other site-specific data required to run the model. Based on examination and evaluation of past documents, the SRS Sanitary Landfill attained a score of 15 according to the U.S.E.P.A (United States Environmental Protection Agency) natural attenuation screening protocol, which implies that there is adequate evidence for anaerobic biodegradation of chlorinated organics. It is therefore assumed that reductive dechlorination under anaerobic conditions is the major means of solvent degradation. As the assumptions of the BIOCHLOR model very closely suits the above conditions, it is selected as a suitable natural attenuation-screening model. 
In Phase III of this thesis BIOCHLOR model was run, and the results are discussed by analyzing the variation of concentration of parent and daughter contaminants over the modeled area for the modeled time period. It is concluded that at many places in the modeled area the concentration of contaminants well exceed the MCL (Maximum Concentration Limit). This contradicts the suitability of MNA as a remedial strategy and prompts identification of other treatment technologies in conjunction with MNA at SRS Landfill Site. 


\section{TABLE OF CONTENTS}

CHAPTER

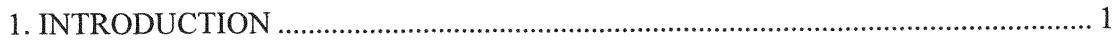

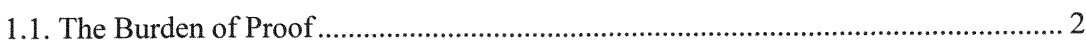

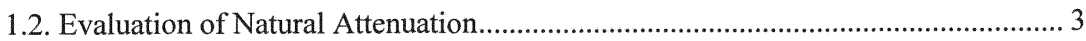

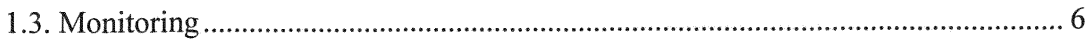

1.4. Natural Attenuation in Conjunction With Active Responses ................................. 7

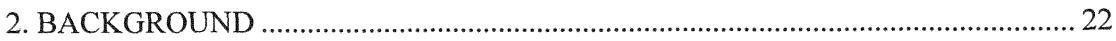

2.1. Approaches for Evaluating Natural Attenuation .................................................. 22

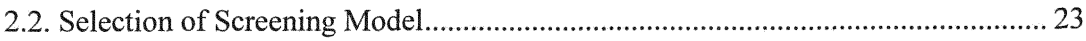

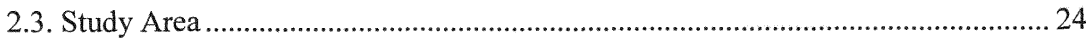

2.3.1. Geologic and Hydrogeologic Framework ..................................................... 25

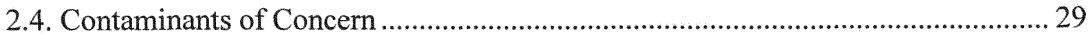

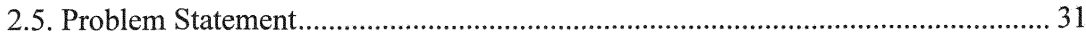

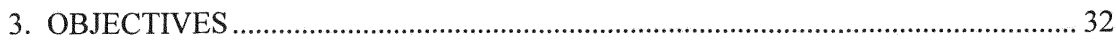

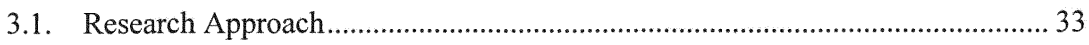

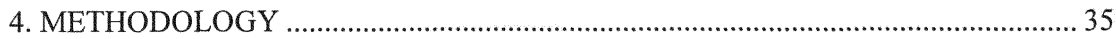

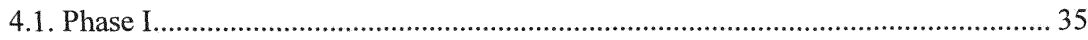

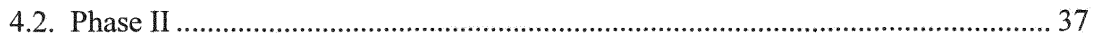

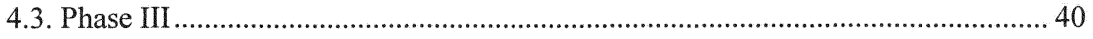

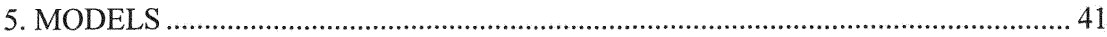

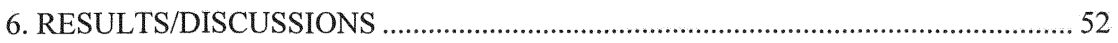

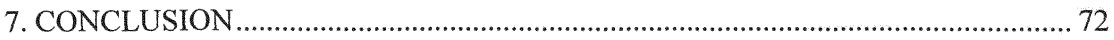


REFERENCES

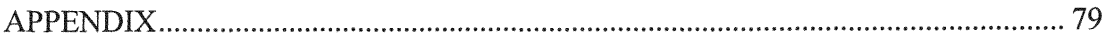




\section{LIST OF TABLES}

TABLE

PAGE

Table 1. Summary of Natural Attenuation Screening Protocol ........................................ 38

Table 2. Score-Interpretation of Chlorinated Organics .................................................... 39

Table 3. Equations and Definitions in BIOCHLOR Model.............................................. 46

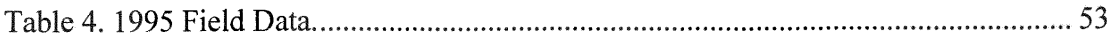

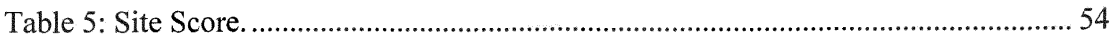

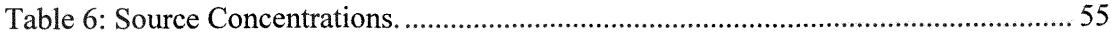

Table 8. Models Current Estimated TCE Concentrations. ...............................................5 57

Table 9. Models Current Estimated DCE Concentrations............................................... 58

Table 10. Models Current Estimated VC Concentrations. ................................................59

Table 11. Models Future Predicted PCE Concentrations. .............................................. 60

Table 12. Models Future Predicted TCE Concentrations................................................. 62

Table 13. Models Future Predicted DCE Concentrations.................................................. 64

Table 14. Models Future Predicted VC Concentrations...................................................6 65

Table 15. Models Future Predicted Ethenes Concentrations...........................................67 67

Table 16. VC Concentrations With Time Period............................................................. 70

Table 17. Sensitivity Analysis Results - Rate Coefficients. ............................................. 71

Table 18. Sensitivity Analysis Results -Retardation factor............................................ 71

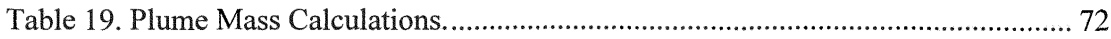




\section{LIST OF FIGURES}

FIGURE

PAGE

Figure 1. Cross Section of Treatment Wall . 12

Figure 2. Typical Thermal Treatment Unit 13

Figure 3. Typical Hydrofracturing Unit 15

Figure 4. Typical Air Sparging Setup 16

Figure 5. Typical Directional Wells 18

Figure 6. Typical In-Well Air Stripping Unit 19

Figure 7. Typical Nutrient Injection Unit . 21

Figure 8. Location of Sanitary Landfill Site 26

Figure 9. Boundaries of sanitary landfill expansion and monitoring wells at the site...... 27

Figure 10. SRS Landfill Map of Cells and the Years Filled 28

Figure 11. Reductive Dechlorination of Common Aliphatic Hydrocarbons 42

Figure 12. Reductive Transformation of Chlorinated Ethenes 43

Figure 13. Initial screening process flow chart 45

Figure 14. Modified Domenico Solution 47

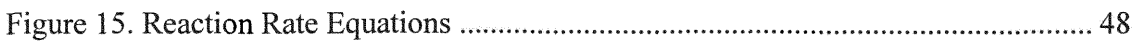

Figure 16. Current Estimated PCE Concentrations Along The Modeled Area................. 56

Figure 17. Current Estimated TCE Concentrations Along The Modeled Area................ 57

Figure 18. Current Estimated DCE Concentrations Along The Modeled Area. .............. 58

Figure 19. Current Estimated VC Concentrations Along The Modeled Area.................. 59

Figure 20. Future Predicted PCE Concentrations Along The Modeled Area................... 60

Figure 21. Future Predicted PCE Concentrations Along Center Line.............................. 61 
Figure 22. Future Predicted TCE Concentrations Along Centerline.

Figure 23. Future Predicted TCE Concentrations Along The Modeled Area................... 62

Figure 24. Future Predicted DCE Concentrations Along The Modeled Area.................. 63

Figure 25. Future Predicted DCE Concentrations Along Centerline................................64

Figure 26. Future Predicted VC Concentrations Along Center Line............................... 65

Figure 27. Future Predicted VC Concentrations Along Centerline...................................66

Figure 28. Future Predicted Ethenes Concentrations Along The Modeled Area. ............. 67

Figure 29. Future Predicted Ethenes Concentrations Along The Modeled Area. .............6 68

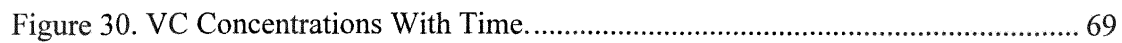




\section{INTRODUCTION}

Natural attenuation is the process of reduction of contaminant concentrations in the environment through biological processes (aerobic and anaerobic biodegradation, plant and animal uptake), physical phenomena (advection, dispersion, dilution, diffusion, volatilization, sorption/desorption), and chemical reactions (ion exchange, complexation, abiotic transformation) (U.S.EPA, 1998).

Natural attenuation is not a no-further-action alternative, which typically requires extensive monitoring to ensure that the predicted natural processes are taking place. Natural attenuation remedies might take a longer time than engineered remedies to correct the problem and additionally, there should be a readily available contingent remedy for the site. To prove that natural processes are sufficient to reduce risk in the time frame required it would take credible site characterization data, scientific data, and predictive modeling.

Interim guidance of United States Environmental Protection Agency (U.S.EPA) addresses the natural attenuation of organic substances, such as fuels and chlorinated solvents, as well as inorganic contaminants, such as metals and radionuclides (U.S.EPA, 1998) .In its policy, U.S.EPA defines natural attenuation to include non-destructive mechanisms, such as dispersion, dilution, sorption, volatilization, and chemical or biological stabilization, as well as the actual degradation of contaminants. However, it suggests that it is not likely to be acceptable if it is a mere reduction in concentration due to plume migration. Most technical experts believe that if significant amount of 
contaminant destruction is anticipated then only natural attenuation should be chosen as a remedy for organic contaminants.

The advantages of natural attenuation include the decrease in generation of remediation wastes, possible reductions in the cross-media transfer of contaminants, and lower remediation costs. The disadvantages include the creation of transformation products which may be more toxic than the original contaminants, slower cleanups which ultimately leads more cleanup time, more costly site characterization, a dependence on uncertain institutional controls to ensure long-term protection, and the chance that subsurface conditions will not support natural attenuation as long as necessary (Wiedemeir et al., 1996).

\subsection{The Burden of Proof}

According to USEPA the party that proposes to select natural attenuation as a cleanup remedy has to bear the burden of proof (U.S.EPA, 1999). Even though natural attenuation in general has both advantages and disadvantages, the proponent must present convincing site-specific technical evidence that natural attenuation will effectively protect human health and the environment and furthermore, that within a reasonable time frame it will achieve remedial objectives. Natural attenuation may be a realistic option at sites where there are no evident exposure pathways, for example, if there is little or no demand for groundwater.

In many common circumstances natural attenuation may not be a desirable remedial alternative at sites where contamination poses an imminent risk to people or the 
environment or where a large plume shows no signs of stabilizing (Groundwater Services, 1998).

U.S.EPA has laid out three important principles that should be considered during a remedy selection, whether or not monitored natural attenuation is being considered as a possible remedial option. They apply irrespective of which statute provides cleanup authority, and no matter which regulatory office is responsible for oversight (U.S.EPA, 1998).

1. Source control actions should be done whenever it is practicable. If treatment is not practicable, then the source should be contained with engineering controls. Natural attenuation is selected if it is ensured that the remedial options remove, treat, or contain the contaminant source.

2. If it is practicable groundwater should be brought to drinking water or similar standards within a reasonable time frame. If restoration is not possible, further plume migration should be controlled and exposure pathways should be interrupted.

3. Soil should be remediated until the level of risk to human and environmental receptors is acceptable and the transfer of contaminants from one medium to another should not result in unacceptable levels of risk.

\subsection{Evaluation of Natural Attenuation}

Selection of monitored natural attenuation does not change or displace these remedy selection principles. In fact monitored natural attenuation (MNA) should be 
evaluated as a remedial option according to the National Contingency Plan (NCP) which establishes the regulatory framework for hazardous waste sites that are regulated under the Resource Conservation and Recovery Act (RCRA) and sites that are regulated under the Comprehensive Environmental Response, Compensation and Liability Act (CERCLA, otherwise known as the Superfund). The NCP does not apply hard and fast formulas to remedy selection instead it identifies factors like effectiveness, feasibility, safety, cost, etc. which must be considered at each site in comparing possible cleanup strategies and technologies.

While considering natural attenuation as a remedial option, U.S.EPA recommends that the proponent project, up front determine whether contamination is likely to break down before it reaches (at hazardous levels) human or ecological receptors. Which implies whether the degradation of contaminants into non-hazardous substances proceeding faster than the rate of migration? But the answer to this question always depends upon the nature of the subsurface environment, different contaminants may respond differently under the same conditions. For example, fuel with benzene, toluene, ethyl benzene, and xylene (BTEX) usually does not sink as far as denser contaminants like chlorinated solvents. As BTEX fuels remain just below the surface, where generally more oxygen available, their breakdown is relatively rapid where as chlorinated solvents, which tend to sink to the bottom of the water table, tend to degrade more slowly (U.S.EPA, 1998).

Where stabilization is a major means of degradation like in metals it should be judged first whether the contamination is likely to be tied up before it reaches receptors 
and second, whether the stabilization process is likely to be permanent (Sandia Report, 1999).

If contamination remains within property boundaries, in the short run it may be more manageable by controlling exposure pathways and minimizing risks to human health and the environment. However as both land use and ownership may change even for large, seriously polluted federal facilities, mere distance from property lines may not make natural attenuation more suitable in the long run.

Degradation itself does not guarantee the protection of human health and the environment because some of the degradation products are more harmful than the original contaminant. For example, vinyl chloride, which is more persistent, more mobile, and more toxic than its parent chlorinated compounds. In fact, it is a confirmed carcinogen (cancer-causing substance)(Vogel, 1994).

In addition plumes may also contain hazardous substances other than the principal contaminant of concern. For example, the gasoline additive methyl tertiary butyl ether (MTBE) has been found in a large number of fuel-contaminated plumes, which not only resists biodegradation but also migrates at a much faster rate than BTEX compounds (Newell et al., 1999).

Therefore natural attenuation must not only be demonstrated to be effective against the original contaminant of concern, but also it must be capable of reducing the risk from degradation products and other contaminants. 


\subsection{Monitoring}

According to U.S.EPA's policy the word "monitoring" to regulators implies that implementing natural attenuation, as a remedial option does not mean that responsible parties can simply walk away from contamination sites. The responsible parties must demonstrate in advance that natural attenuation is likely to protect public health and the environment, and also must show, after approval, that it's working as advertised.

In its policy U.S.EPA recommends that monitoring be designed to accomplish the following (U.S.EPA, 1998):

- Identify potentially toxic transformation products.

- Determine whether the plume is expanding either laterally and vertically.

- Ensure that the effect on downstream receptors is nil.

- Detect any new releases that could affect the remedy. Changes in hydrogeological, geochemical, or microbiological parameters are to be detected which might reduce the effectiveness of natural attenuation. Even though U.S.EPA's Monitored Natural Attenuation guidance lists several factors that should be considered in monitoring performance, it does not explicitly require monitoring to prove that attenuation is only due to biological activity nor does it specify what level of certainty is adequate to verify that natural attenuation is occurring. 
In summary U.S.EPA's policy on natural attenuation is still essentially in draft form and also even if it's adopted as is, the affected communities if attentive, informed, and organized will have an ample opportunity to question the selection of monitored natural attenuation as a remedy.

Presently MNA have been selected at sites that are contaminated with organic contaminants like pesticides, benzene and benzene derivatives (BTEX) in gasoline, polycyclic aromatic hydrocarbons (PAH), and chlorinated solvents such as tetra- and trichloroethylene (PCE and TCE). Inorganic contaminants like metals, which cannot be degraded but may be transformed into different chemical forms, which are nontoxic or immobile, or are physically unavailable for uptake by organisms. For example, chromium (VI) is mobile in groundwater and because of its carcinogenicity presents a significant health risk. In subsurface environments that are depleted of oxygen like wetlands associated with floodplains, the chromium (VI) is reduced to chromium (III), which is significantly less toxic and relatively immobile because of its strong binding to minerals (National Research Council, 1993).

\subsection{Natural Attenuation in Conjunction With Active Responses}

Natural attenuation may be acceptable as a supplement to active responses even where and when it is not likely, by itself, to meet cleanup goals. As natural attenuation occurs regardless of regulatory approval, it is probably responsible for measurable reductions of concentration, toxicity, or mobility at even those sites with the most active remediation programs. In addition if natural attenuation proves inadequate, active responses may be adopted as back-ups. As a remedial option monitored natural 
attenuation may be possible in conjunction with more active responses in four types of situations:

1. At outer portions of contaminant plumes that may be left to natural attenuation, as the contaminant concentrations are very low at these locations while the rest of the plume is subjected to extensive treatment.

2. After active remediation has run its course and if monitoring shows that the active remedies are no longer bringing significant or even measurable improvements then natural attenuation might be relied upon to finish the job.

3. Natural attenuation may be enhanced through the application of oxygen or other substances. Under certain conditions adding oxygen to the soil or groundwater may dramatically speed biodegradation. Adding oxygen and methane to the subsurface environment may also enhance cometabolism. And injecting chemical nutrients into the soil or groundwater may also accelerate anaerobic degradation.

4. U.S.EPA recommends that a contingency remedy selection should also be made when monitored natural attenuation is adopted as a remedy, which would be implemented, without further consideration of remedial alternatives, if monitoring shows that natural attenuation fails to perform as anticipated. The contingency remedy should not only specify the alternate strategy but also contain clear criteria for triggering its implementation. Those criteria should address trends in concentration of contaminants at specified locations, indications of new releases, indicators of renewed contaminant 
migration, rates of degradation relative to remediation objectives, and proposed changes in land use.

The U.S.EPA's policy states that monitored natural attenuation is appropriate when it is protective of human health and is capable of achieving remediation goals within a time frame that is reasonable compared to other alternatives however it also states that the reasonableness of the remediation time frame should be evaluated on a sitespecific basis. Factors that should be included during the selection are (U.S.EPA, 1998):

1. Nature of the affected resource (e.g., is it a potential source of drinking water?);

2. Uncertainties regarding the quantity of contamination; and

3. The reliability of monitoring and institutional controls over a long period.

Even when natural attenuation compares favorably to a conventional remedial strategies like pump-and-treat, it may also be necessary to consider innovative alternatives because over-reliance on natural attenuation could stifle the development of new cleanup technologies. Many of present day available remedies accomplish cleanup tasks that were considered to be impossible or at least not feasible, when cleanup laws and standards were originally promulgated. If natural attenuation has been considered by default at sites where these remedies have been proven, these technologies would not be available today. If natural attenuation is selected as the remedial strategy it may make sense to review this strategy periodically to ensure that new technologies are not being overlooked. 
Other Available Treatment Technologies for Removal of Chlorinated Solvents in Groundwater:

Treatment technologies that are used to remove chlorinated solvents from groundwater can be categorized in to:

1. In situ processes

2. Ex situ process

In situ process:

- In these processes groundwater is treated without being brought to surface

- Significant cost savings

- Longer time periods

- Less certainty in uniformity of treatment because of the variability in aquifer characteristics

- Difficult to check the efficiency of process

Ex situ process:

- Contaminated groundwater is brought to the surface and treated

- High treatment cost

- Shorter time periods

For the present site conditions the time required is not deciding factor compared to cost, hence in situ treatment technologies are preferred to ex situ. In situ treatments are categorized in to:

- Physical/chemical treatment 
- Separation techniques

Physical/chemical treatment involves the use of the physical properties of contaminants or the contaminated medium to destroy (i.e., convert chemically) or separate the contamination. Prominent treatment technologies in this category are:

- Passive/Reactive Treatment Walls

- Thermal Treatment

- Hydrofracturing

Separation techniques involve separation of the contaminant from groundwater. Prominent treatment technologies in this category are:

- Air Sparging

- Directional Wells

- In-Well Air Stripping

\section{Passive/Reactive Treatment Walls:}

Description:

In this technology a permeable reaction wall is installed across the flow path of contaminant plume. These barriers allow the passage of water while restricting the movement of contaminants by employing agents like zero-valent metals, sorbents, microbes, and others (FRTR, 2002a)

Typical passive treatment wall can be observed in Figure 1. 


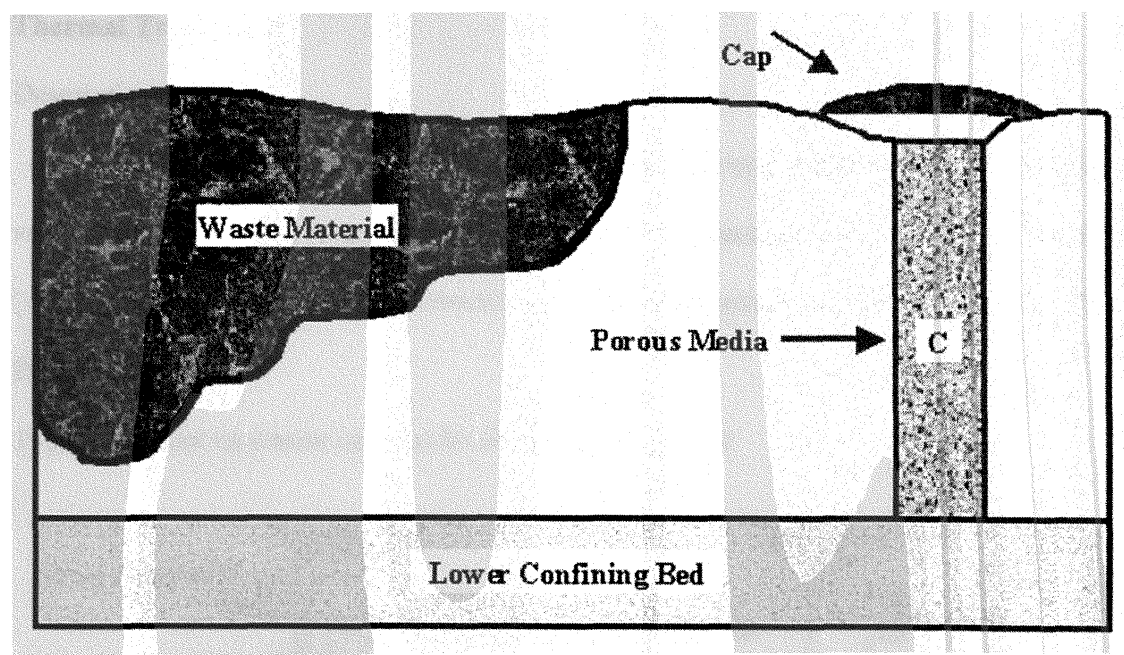

Figure 1. Cross Section of Treatment Wall (Source: FRTR, 2002a).

Applicability:

More applicable to VOC's, SVOC's and inorganics.

Limitations:

- Replacement of the reactive medium due to loss in reactive capacity of treatment walls

- $\quad$ Precipitation of metal salts may decrease the treatment wall permeability

- $\quad$ Depth and width of permeable barrier

- Volume cost of treatment medium

- $\quad$ Permeability of the passive treatment wall gets affected due to biological activity or chemical precipitation

Cost:

Not available 


\section{Thermal Treatment:}

Description:

In this technology steam is forced in to aquifer through injection wells to vaporize volatile and semi-volatile contaminants. Vaporized contaminants rise to the unsaturated (vadose) zone where they are removed by vacuum extraction and then treated (FRTR, 2002b).

Typical thermal treatment unit can be observed in Figure 2.

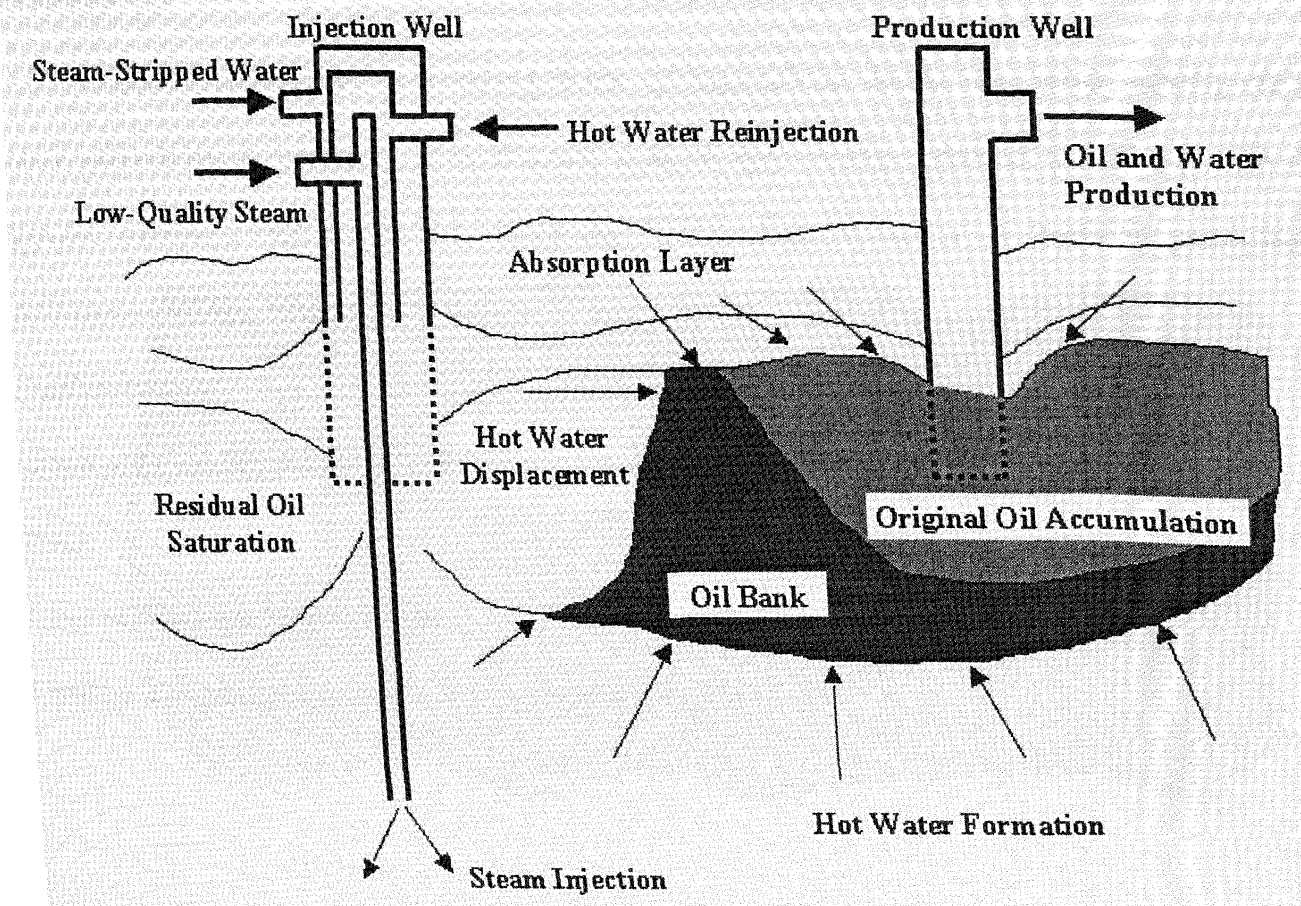

Figure 2. Typical Thermal Treatment Unit (Source: FRTR, 2002b).

Applicability:

More applicable to VOC's, SVOC's and fuels. 
Limitations:

Process effectiveness is impacted by soil type, contaminant characteristics and concentrations, geology, and hydrogeology.

Cost:

$\$ 100-\$ 300$ per cubic yard.

\section{Hydrofracturing:}

Description:

In this technology pressurized water is injected to crack low permeability and over consolidated sediments. The fissures created due to this process are filled with a porous medium, which serves as substrates for bioremediation or to improve pumping efficiency (FRTR, 2002c).

Applicability:

Applicable to wide range of contaminant groups.

Cost:

Cost per fracture $\$ 1000-\$ 1500$.

Typical hydrofracturing unit can be observed in Figure 3. 


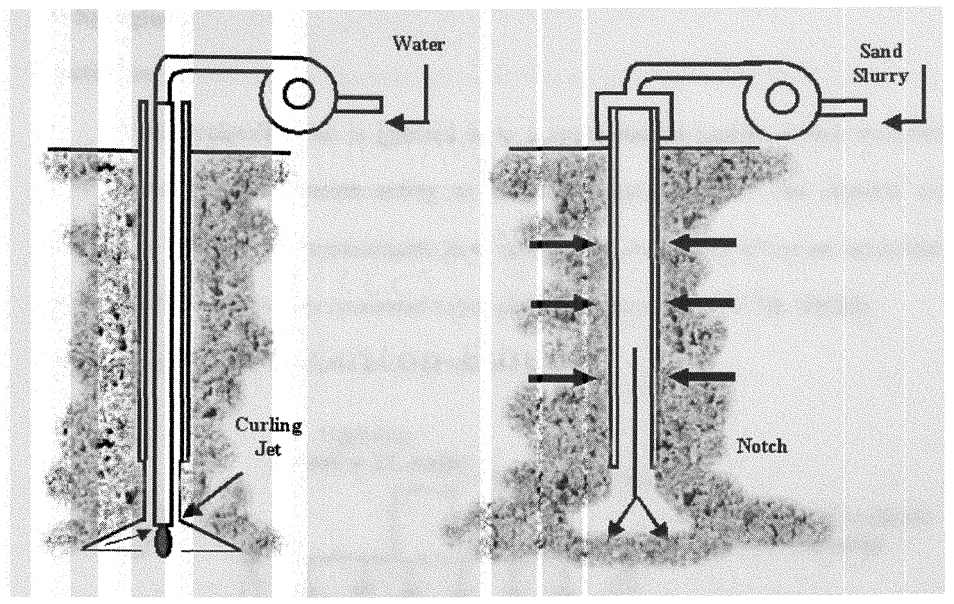

Figure 3. Typical Hydrofracturing Unit (Source: FRTR, 2002c).

Limitations:

- Not applicable to bed rock susceptible to seismic activity

- Investigations are necessary to identify the existence of underground utilities, structures, or trapped free product

- Potential in developing new pathways leading to the unwanted spread of contaminants

- Low permeability locations may still remain after using this technology

- Inability in controlling the location or size of fractures created

- Possibility of collapse of fractures due to overburden pressure 


\section{Air Sparging:}

Description:

In this technology air is injected in to a contaminated aquifer, which removes contaminants, by volatilization acting as an underground stripper. The injected air facilitates in flushing the contaminants in to unsaturated zone from where an extraction system is used to remove the generated vapor phase contamination (FRTR, 2002d).

Typical air sparging system can be observed in Figure 4.

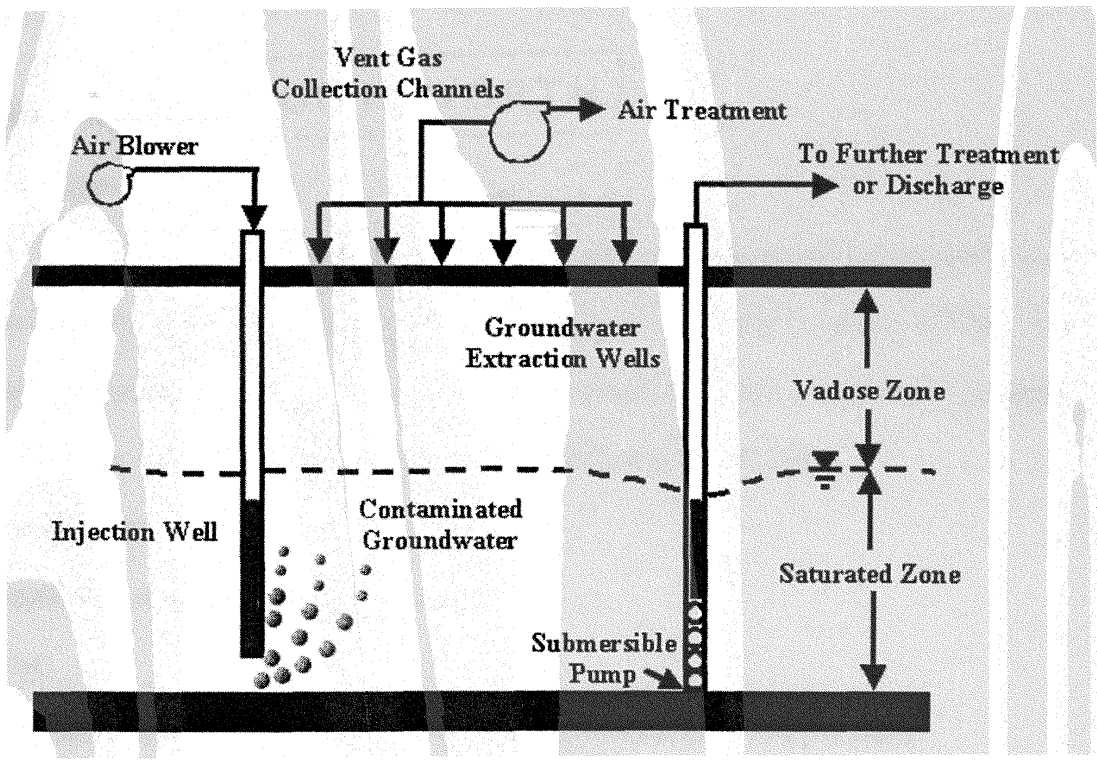

Figure 4. Typical Air Sparging Setup (Source: FRTR, 2002d).

Applicability:

Target contaminants are VOCs and Fuels. 
Limitations:

- Possibility of uncontrolled movement of potentially dangerous vapors

- Site geology and depth of contaminants are needed for consideration

- $\quad$ The design of air injection wells is site specific

- Soil heterogeneity may lead to ineffectiveness in some zones

Cost:

Range varies from $\$ 371,000$ - $\$ 865,000$ per hectare.

\section{Directional Wells:}

Description:

In this technology drilling techniques are used to position wells horizontally, or at an angle, to reach contaminants that are not accessible by direct vertical drilling. It is used to enhance other in-situ or in-well technologies like groundwater pumping, bioventing, SVE, soil flushing, and in-well air stripping (FRTR, 2001).

Applicability:

Applicable to all range of contaminants.

Cost:

Estimated cost $\$ 60-\$ 250$ per meter drilling and for installing $\$ 164$ per meter. Typical directional wells can be observed in Figure 5. 


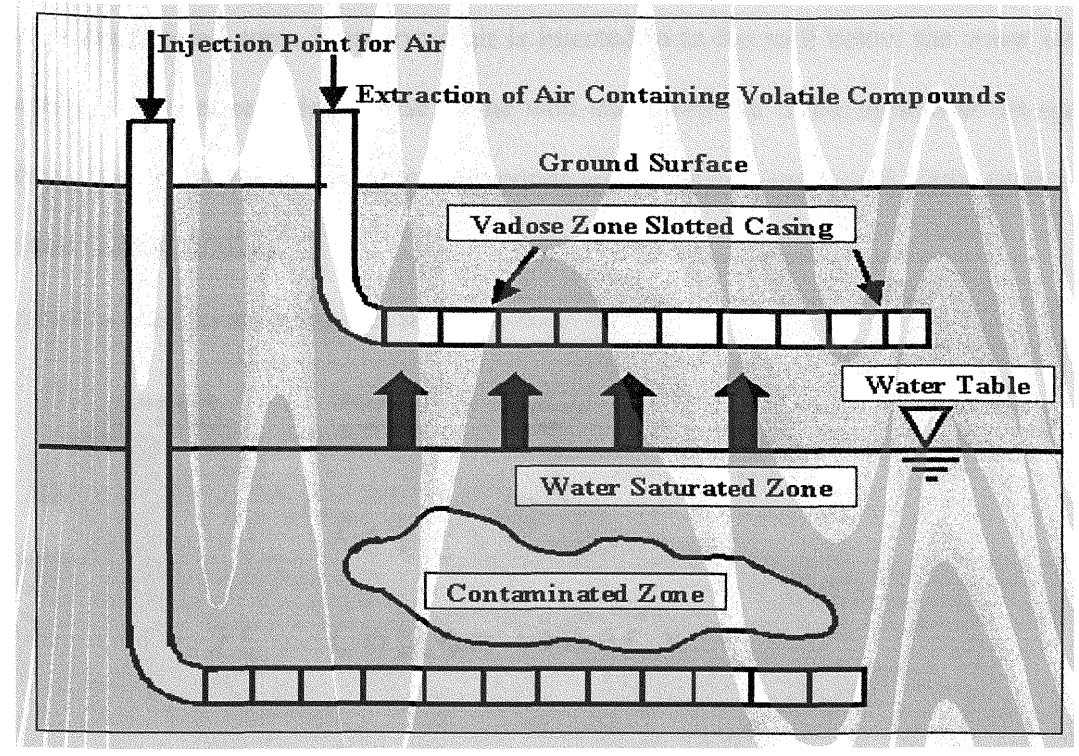

Figure 5. Typical Directional Wells (Source: FRTR, 2001).

\section{Limitations:}

- Potential for the wells to collapse

- $\quad$ Requirement for specialized equipment

- Difficult to position wells precisely

- Installation of wells costly

- Limited to depths less than 50 feet

\section{In-Well Air Stripping:}

Description

In this technology air is injected in to a vertical well, which has been screened at two depths. The lower end of screen is set in the groundwater saturated zone and upper 
end in unsaturated zone. Pressurized air is injected in to the well below the water table, aerating the water resulting in rise in the well and flows out of the system at the upper screen. Vapors of volatile organic compounds are extracted using soil vapor extraction system (FRTR, 2002e).

Typical in-well air stripping can be observed in Figure 6.

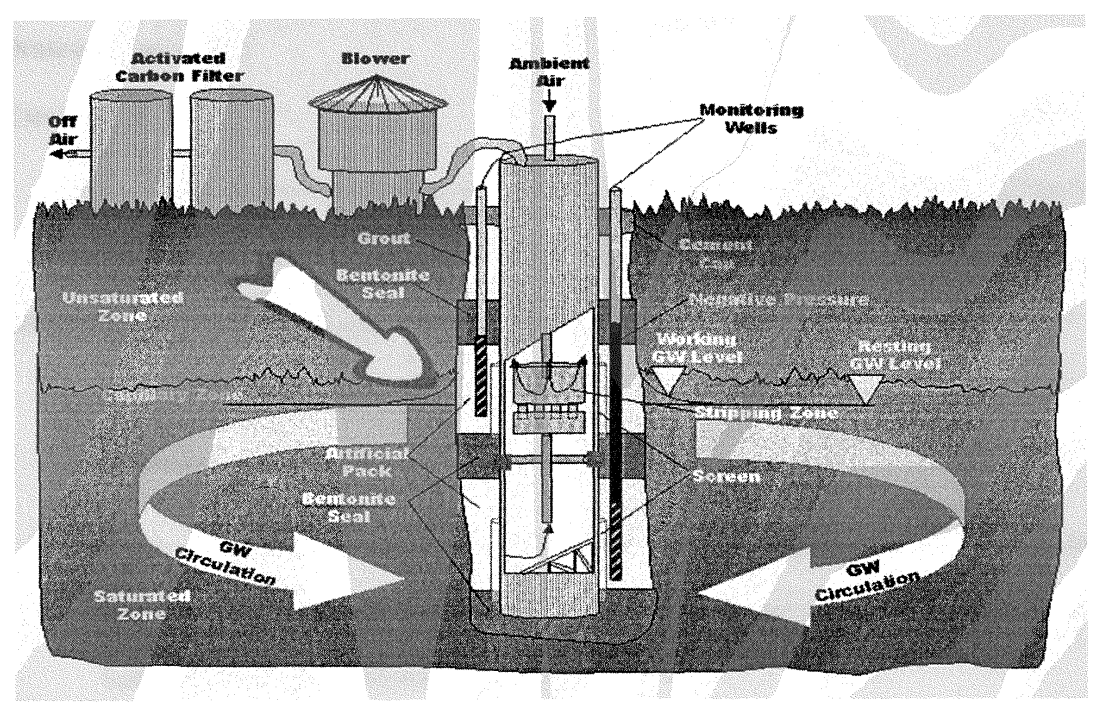

Figure 6. Typical In-Well Air Stripping Unit (Source: FRTR, 2002e).

Applicability:

Applicable to haloginated VOC's, SVOCs, and Fuels.

Limitations:

- More effective at sites containing high concentrations of dissolved contaminants having a high Henry's law constants

- Fouling of the system is possible due to infiltration precipitation of oxidized constituents 
- Shallow aquifers may limit process effectiveness

- May not be efficient at sites with strong natural flow patterns

Cost:

Not available.

\section{Nutrient Injection:}

Description:

In this technology nutrients are injected in gaseous form to enhance bioremediation. This technology is a combination of 3 emerging technologies like air stripping, horizontal wells, and bioremediation (FRTR, 2002f).

- Horizontal wells are provided to increase the effectiveness in accessing subsurface contamination.

- The air sparging/gaseous nutrient injection processes are used to eliminate the need for surface ground water treatment systems and treats the subsurface of both saturated and unsaturated zones.

- The growth of indigenous microorganisms in the contaminated zone is stimulated by air sparging/gaseous nutrient injection, which in turn degrades and mineralizes VOC's. The injection process is combined with soil vapor extraction to strip higher concentrations. Based on site-specific requirements the injection/extraction system can be designed.

Typical nutrient injection setup can be observed in Figure 7. 
- Shallow aquifers may limit process effectiveness

- May not be efficient at sites with strong natural flow patterns

Cost:

Not available.

\section{Nutrient Injection:}

Description:

In this technology nutrients are injected in gaseous form to enhance bioremediation. This technology is a combination of 3 emerging technologies like air stripping, horizontal wells, and bioremediation (FRTR, 2002f).

- Horizontal wells are provided to increase the effectiveness in accessing subsurface contamination.

- The air sparging/gaseous nutrient injection processes are used to eliminate the need for surface ground water treatment systems and treats the subsurface of both saturated and unsaturated zones.

- The growth of indigenous microorganisms in the contaminated zone is stimulated by air sparging/gaseous nutrient injection, which in turn degrades and mineralizes VOC's. The injection process is combined with soil vapor extraction to strip higher concentrations. Based on site-specific requirements the injection/extraction system can be designed.

Typical nutrient injection setup can be observed in Figure 7. 


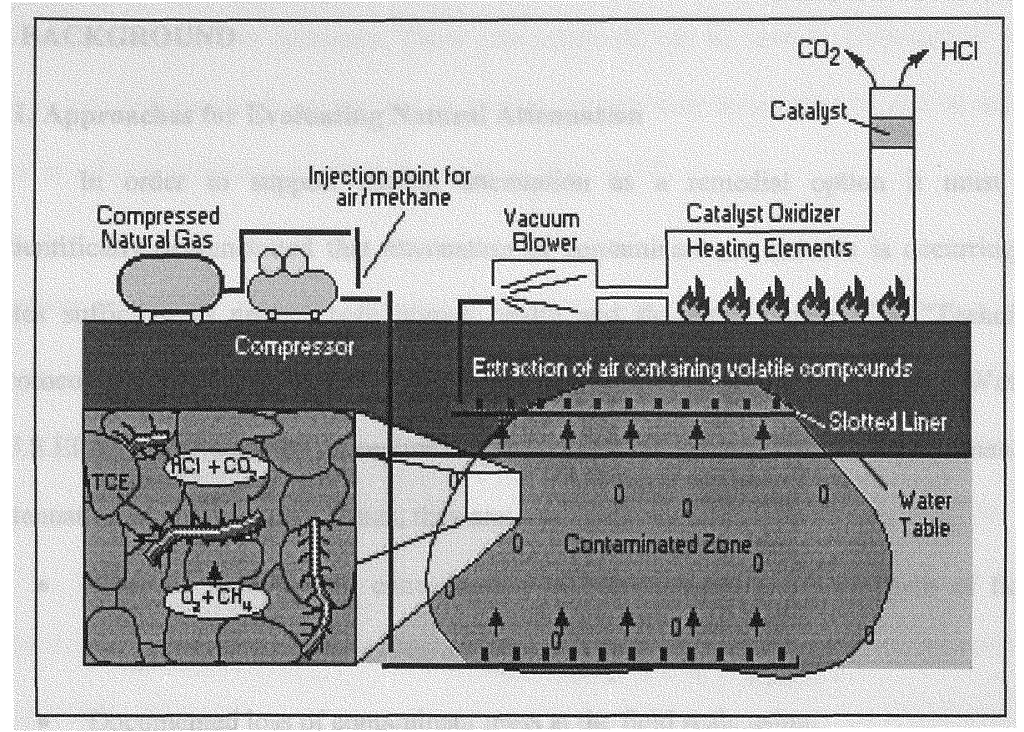

Figure 7. Typical Nutrient Injection Unit (Source: FRTR, 2002f).

Applicability:

Sites containing moderately permeable, relatively homogenous sediments contaminated with VOC's.

Limitations:

- Difficulty in precise placing of well.

- $\quad$ Potential for the wells to collapse.

- May not be efficient at sites with strong natural flow patterns.

Cost:

Varies. 


\section{BACKGROUND}

\subsection{Approaches for Evaluating Natural Attenuation}

In order to support natural attenuation as a remedial option it must be scientifically demonstrated that attenuation of contaminants in the site is occurring at rates sufficient to protect both human health and the environment. The "Technical Protocol For Evaluating Natural Attenuation of Chlorinated Solvents in Ground Water" (U.S.EPA, 1998) suggests three lines of evidence that can be used to support natural attenuation of chlorinated solvents, they are:

- Observed reduction in concentration of contaminants along the path of flow, downgradient from the source of contamination.

- Documented loss of contaminant mass at the field scale using:

1. Chemical and geochemical analytical data to support decrease in parent compound concentration, increase in daughter compound concentrations, depletion of electron acceptors and donors, and increase in metabolic byproduct concentrations; and/or

2. Estimation of residence time of the contaminant along the flow path to document its decrease and to calculate biological decay rates at the field scale.

- Laboratory microcosm or field data to support the occurrence of biotransformation and in estimation of biotransformation rates.

Investigators must obtain at a minimum first two lines of evidence or the first and third lines of evidence. The second or third line of evidence is pivotal as it provides 
biotransformation rate constants. These rate constants can be used in conjunction with other fate and transport parameters to predict contaminant concentration and to assess risk at a downgradient point of exposure (U.S.EPA, 1998).

Various approaches used for obtaining these lines of evidence are:

- Direct field measurements to demonstrate contaminant losses

- Field data combined with models of the subsurface, to link the observed decrease in contaminant concentrations to the underlying mechanisms responsible for contaminant losses

The first approach described above is difficult or impossible; hence the second approach is generally followed.

\subsection{Selection of Screening Model}

Selection of natural attenuation models depends on the nature of contaminants and selection of their level of detail of data and analysis required depends on the complexity of the site.

Some of the models presently available are:

- BIOCHLOR

- BIOPLUME

- BIOSCREEN

- ART3D with MODFLOW

- MT3D with MODFLOW 


\subsection{Study Area}

The Savannah River Site is owned by U.S.Department of Energy (DOE) and operated by Westinghouse Savannah River Company. The site has mainly been used for the production of nuclear materials for national defense, medical research, and space exploration. The SRS site is approximately 320 square miles in area and is located in a rural area along the Savannah River, principally in the Aiken and Barnwell counties of South Carolina (U.S.DOE, 2001).

The Sanitary Landfill in the site began operations in 1974 and received solid waste from site construction areas, offices, shops, and cafeterias. During the course of its operation, the landfill received rags and wipes used with F-listed solvents (WSRC, 1993a).

In 1988 the sanitary landfill was designated as a Resource Conservation and Recovery Act (RCRA) Solid Waste Management Unit due to recurring evidence of hazardous constituents in the groundwater beneath the site. In 1994, a RCRA Corrective Action Plan (CAP) was submitted to the South Carolina Department of Health and Environmental Control (SCDHEC). The CAP defined the necessary actions to reduce the concentrations of contaminants like trichloroethylene and vinyl chloride below Groundwater Protection Standards (GWPS). One of the suggested remedial technologies for the landfill was monitored natural attenuation.

The sanitary landfill is approximately 70 -acres in area and is located between B Area and Upper Three Runs Creek. It was originally opened in 1974 as a 32- acre site and when the original area reached its capacity, a 16-acre Northern Expansion and 22- 
acre Southern Expansion were added in 1987. The Southern Expansion stopped receiving the waste from 1993. The Northern Expansion also known as the Interim Sanitary Landfill even though open, is not receiving waste on a regular basis which is currently under rigorous administrative control to ensure that hazardous waste is not accepted. The location of site can be observed in Figure8, the boundaries of original landfill in Figure 9, landfill map of cells and years filled in Figure 10. At present a subcontractor removes all sanitary wastes from SRS to a controlled landfill off-site (U.S.DOE, 2001).

\subsubsection{Geologic and Hydrogeologic Framework}

The geologic and hydrogeologic characteristics of the site are important as they influence migration and transport of contaminants.

\section{Geologic Setup}

The sanitary landfill is elevated approximately 240 feet above mean sea level (msl) at the northwestern corner, and decreases gradually to 170 feet above msl at the southeast corner. Wetland to the south of landfill makes up the floodplain for Upper Three Creek in this vicinity. This flood plain and creek downgradient of the sanitary landfill are believed to constitute the discharge region for groundwater (in the Steed Pond Aquifer).

\section{Hydrogeologic Setup}

The Steed Pond Aquifer (Water Table Aquifer) is the shallowest hydrostratigraphic unit underlying the landfill, which comprises a saturated unit 
extending from the water table down to the top of the principle-confining unit (Meyers Branch Confining System).

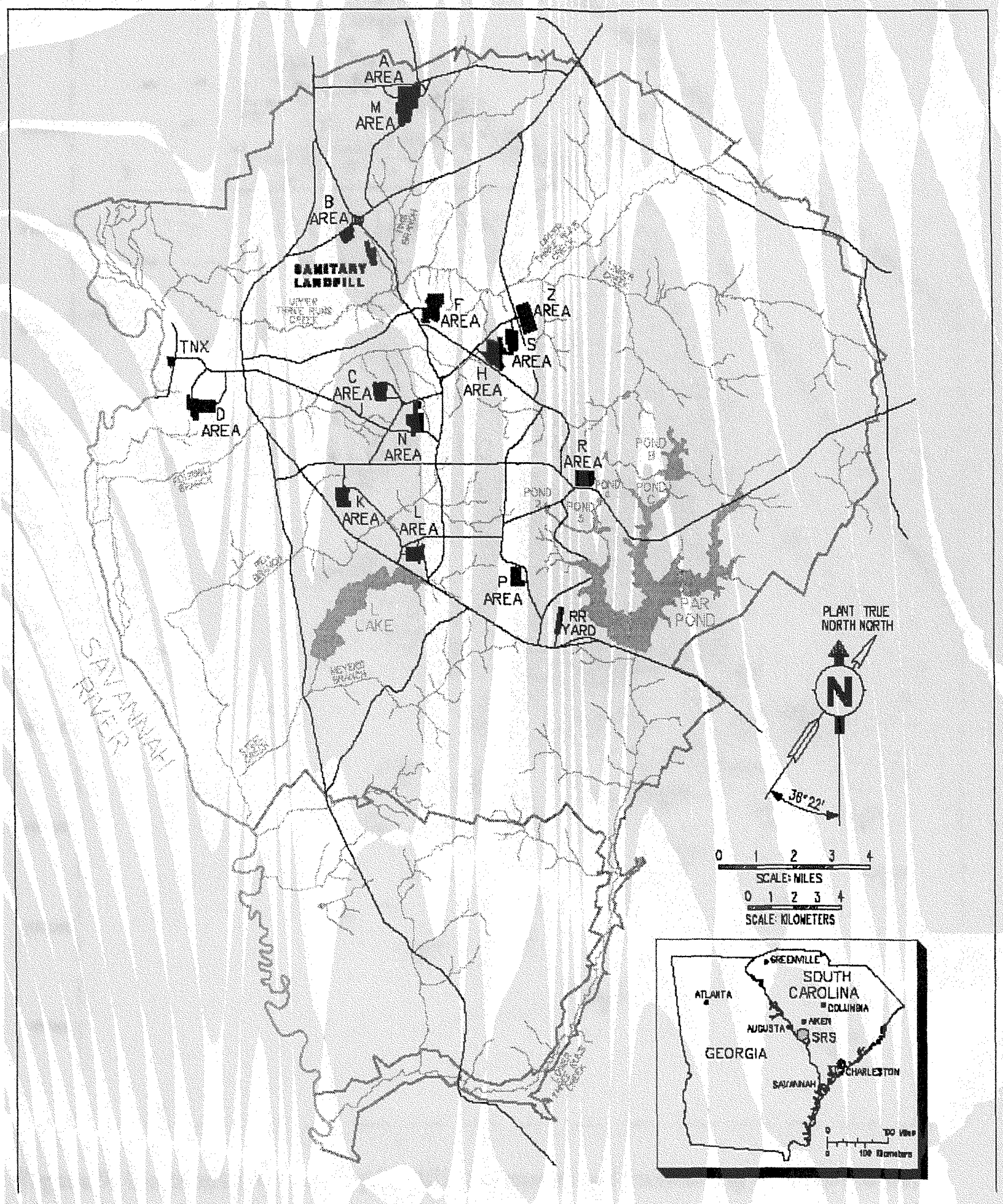

Figure 8. Location of Sanitary Landfill Site (Source: SRS, 1996). 


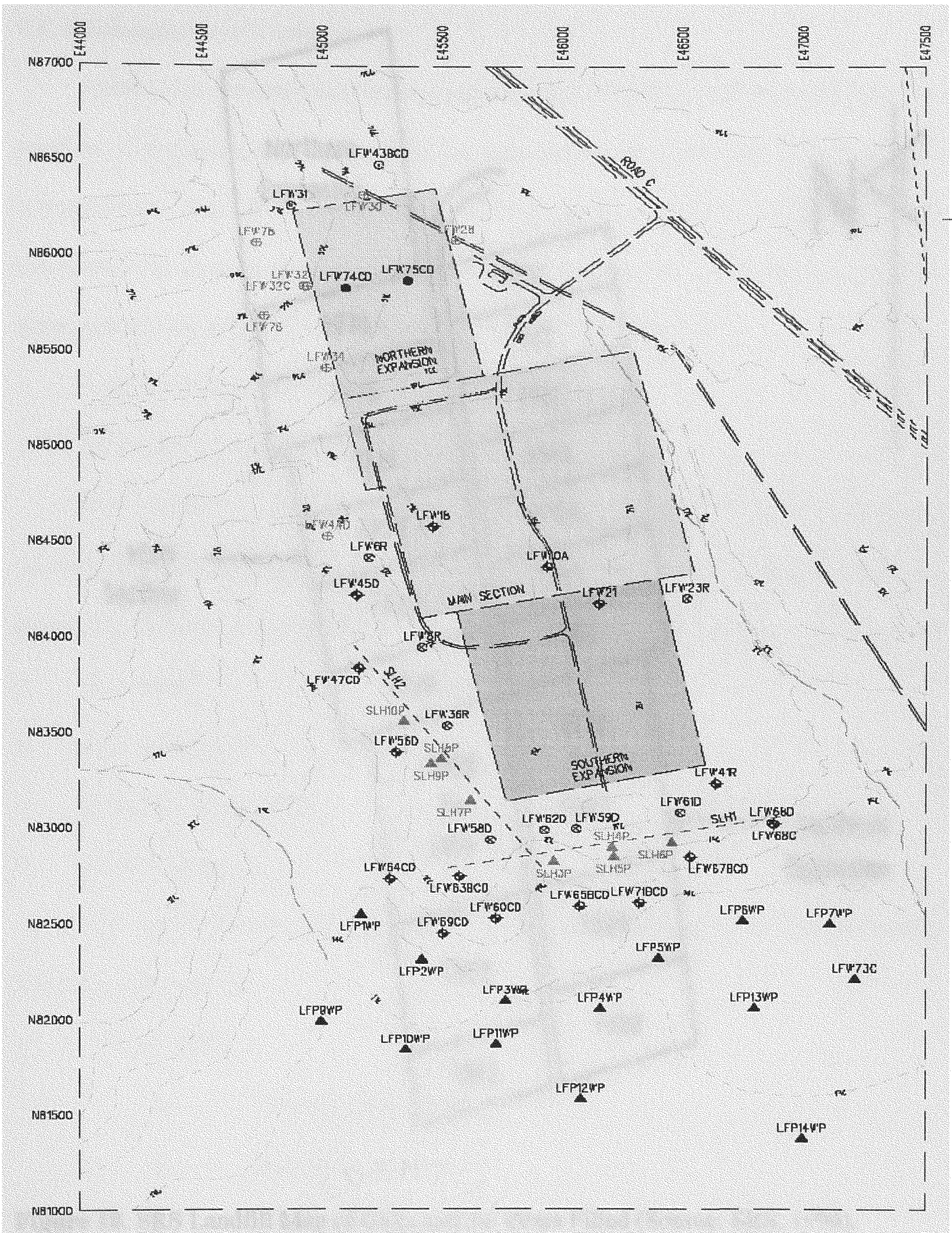

Figure 9. Boundaries of sanitary landfill expansion and monitoring wells at the site (Source: SRS, 1996). 


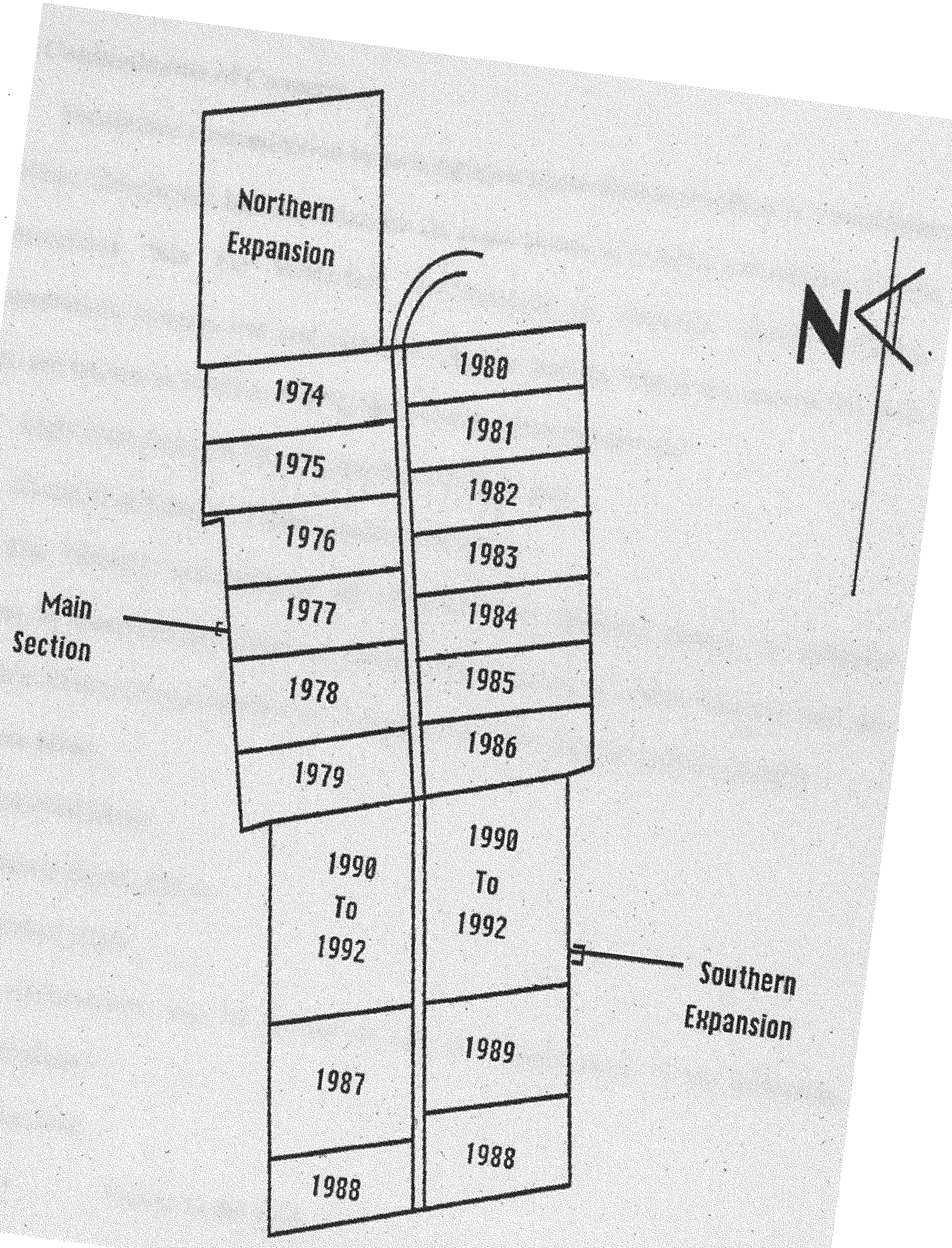

Figure 10. SRS Landfill Map of Cells Years Filled (Source: SRS, 1996). 


\subsection{Contaminants of Concern}

Subsurface contamination by non-aqueous phase liquids (NAPLs) is a worldwide problem. Chlorinated hydrocarbons are the main source of NAPLs and release of these hydrocarbons into the subsurface environment is common during refining, transportation, storage, use and disposal. Organic liquids, which are immiscible with water, are known as NAPLs. NAPLs are classified into two groups:

- Light Non Aqueous Phase Liquids (LNAPLs), and

- Dense Non Aqueous Phase Liquids (DNAPLs)

The DNAPL contaminants get distributed in different phases, in different locations by transport and chemical transformation processes when released into the subsurface. Once released into the environment, DNAPLs may be present as either:

$\circ \quad$ Free phase

- Dissolved phase

- Gaseous phase, and /or

- Adsorbed phase

The contaminants may be present in one or a combination of the following locations and phases:

- $\quad$ Vadose zone

- Vapors in the void

- $\quad$ Free product in the void

- $\quad$ Dissolved in soil moisture

- $\quad$ Adsorbed on the soil matrix

- $\quad$ Floating on top of the capillary fringe. 
- Groundwater
- Dissolved in the groundwater
- Adsorbed onto the aquifer material

Viscosity and water solubility affect the DNAPL transport in the subsurface. Additionally, many factors would affect its movement both at the idealized pore scale and at the realistic field scale conditions. Factors like density, viscosity, interfacial tension, wettability, saturation and residual saturation, relative permeability are important at the pore scale. The effects of DNAPL properties at the field scale on flow can be examined using a simplified version of Darcy's Law:

$$
v=(\mathrm{krg} / \mathrm{m}) \mathrm{dh} / \mathrm{dl}
$$

Where $v$ : flow velocity

$$
\begin{array}{ll}
k: & \text { intrinsic permeability } \\
r: & \text { density of NAPL } \\
g: & \text { force of gravity } \\
m: & \text { viscosity }
\end{array}
$$

$d h / d l$ : hydraulic gradient of NAPL mass

The Darcy's flow velocity increases with increase in density of the DNAPL, but decreases with increase in viscosity of the DNAPL. At the field scale, flow of the DNAPLs is also affected by additional factors such as volume and rate of DNAPL release, infiltration area, formation properties and variability (Mercer and Cohen, 1990). 
DNAPLs generally settle at the bottom of the water table due to higher density than water and flow along the hydraulic gradient. DNAPL migration is affected by heterogeneity of the subsurface, species absorption and solubility, and molecular weight, structure, and other properties control the sorption characteristic of organic compounds. Low solubility leads restricted contaminant migration. DNAPLs prefer entering coarser-grained sediment to fine-grained sediment. Subsequent to the release of contaminants, DNAPLs move downwards, pulled by the force of gravity, until it reaches below the water table. DNAPL heads will build up when sufficient quantity of DNAPL is released, which will cause lateral spreading along the water table. The result is that the contaminant slowly spreads throughout the subsurface environment. Much of the hydrocarbon phase may remain trapped within the subsurface porous media by capillary forces and act as a continual source of pollutants through phase partitioning (Bear, 1979).

\subsection{Problem Statement}

The present applied technologies like pump-and-treat for the removal of contaminants like TCE are being found too costly and also not producing the expected removal results, which compels us to look for other remedial options like monitored natural attenuation. The ineffectiveness of pump-and-treat is due primarily to the huge density difference between TCE and water, which makes only a small fraction of TCE present in the pumped water, and results in increased and more costly duration (National Academy Press, 2000). 


\section{OBJECTIVES}

The objective of this research is to assess the feasibility of monitored natural attenuation (MNA) as a remedial option at Savannah River Site's (SRS) Sanitary Landfill, using an appropriate natural attenuation screening model.

These objectives are met through the implementation of a detailed plan of study, which is described below:

\section{Phase I}

Primary objectives for this phase are to identify and investigate the nature and type of contaminants existing at the site, and collection of the hydrogeologic, dispersivity, adsorption, biotransformation, general, field, and source data to run the model. In cases where site-specific data were unavailable, literature values were used.

\section{Phase II}

Depending on the nature of contaminants and the existing biological conditions, the appropriate natural attenuation screening tool was selected. The existing biological conditions were required and the major means of degradation of contaminants. Execution of the model used field data, and the results are discussed in Phase III.

\section{Phase III}

The results of this phase are analyzed by observing the variation of concentration of the parent and daughter compounds over the entire modeled area for the modeled period of time. Evaluations were done whether there was sufficient evidence to show that MNA is feasible option or not, using all available models or site assumptions. 


\section{Sensitivity Analysis}

Finally, sensitivity analysis was done on the model to observe the model's sensitivity to input parameters.

\subsection{Research Approach}

The Phase I objectives aimed at investigating the physical evidence for potential environmental impairment. Based on existing SRS records this study sought to examine and evaluate the following:

- The local geologic and hydrogeologic regime for understanding the fate and transport of contaminants of concern.

- The results of past hydrological investigations, surface/subsurface sampling as well as laboratory chemical analysis data in understanding the nature concentration of contaminants.

The Phase II objective was aimed at examination and evaluation of past documents. The data obtained in this phase was used for assigning a score to the Landfill Site considering U.S.EPA natural attenuation screening protocol in this account. This was vital as it determines the major means of solvent degradation that ultimately dictates the selection of natural attenuation screening protocol.

Finally, this study attempted to:

- Understand the movement of a plume and the concentration of parent and daughter compounds over the modeled area for the modeled period of time; 
- Make recommendations regarding the feasibility of MNA as a remedial option in the required time frame;

- Make a sensitivity analysis to observe the models sensitivity to various input parameters. 


\section{METHODOLOGY}

\subsection{Phase I}

In this phase the major contaminants present at the sanitary landfill were obtained by reviewing the records and reports. The below data is considered central to this study:

\section{- Hydrogeologic Data}

Hydrogeologic data refers to movement of groundwater. The movement of groundwater below the subsurface is represented by a seepage velocity term, which is equal to the Darcy velocity divided by effective porosity. Darcy velocity is the product of hydraulic conductivity and hydraulic gradient.

$$
\mathrm{V}_{\mathrm{s}}=\mathrm{V} / \mathrm{n}=\mathrm{Ki} / \mathrm{n}
$$

Where:

$$
\begin{array}{ll}
\mathrm{V}_{\mathrm{s}} & \text { Seepage Velocity } \\
\mathrm{n}: & \text { Effective Porosity } \\
\mathrm{K}: & \text { Hydraulic Conductivity } \\
\mathrm{i}: & \text { Hydraulic Gradient }
\end{array}
$$

\section{- Dispersivity Data}

Dispersivity refers to the spatial distribution of dissolved solvent along flow longitudinally (along the direction of ground-water flow), transversely (perpendicularly to ground- water flow), and vertically (downward), due to mechanical mixing and chemical diffusion in the aquifer. These processes define the plume shape, which is the spatial distribution of dissolved mass in the aquifer.

Alpha x: Longitudinal Dispersivity 
Alpha y: Transverse Dispersivity

Alpha z: Vertical Dispersivity

\section{- Retardation Factor}

Adsorption refers to the reduction of concentration of the dissolved contaminants moving through the groundwater. The retardation factor is defined as the ratio of the groundwater seepage velocity to the rate at which organic chemicals migrate in the groundwater. Aquifer and constituent properties both affect the degree of retardation.

$$
\mathrm{R}=1+\left(\mathrm{K}_{\mathrm{d}} \mathrm{B}_{\mathrm{d}}\right) / \mathrm{n}
$$

Where:

$$
\mathrm{K}_{\mathrm{d}}=\mathrm{Koc}^{*} \mathrm{foc}_{\mathrm{oc}} \text { and }
$$

$\mathrm{K}_{\mathrm{d}} \quad$ Distribution Coefficient

Koc: Organic Carbon-Water Partition Coefficient

$\mathrm{f}_{\mathrm{oc}} \quad$ Fraction Organic Carbon on Contaminated Soil

$B_{d}: \quad$ Bulk Density

\section{- Biotransformation Data}

Biotransformation refers to transformation of parent contaminants into daughter products. The transformation of dissolved constituents is assumed to obey first-order decay process, and the transformation coefficient equals 0.693 divided by the half-life of the contaminant in groundwater. As the dissolved solvent is assumed to undergo first order decay only, the rate of biotransformation depends on the concentration of the contaminant and the rate coefficient. In the case of sequential, first-order decay not only the solvent is assumed to degrade by first-order kinetics but also by being simultaneously produced by the first-order decay of the preceding compound. 


\section{- General Data}

General data refers to physical dimensions of the rectangular area to be modeled, and the simulation time for which the concentrations are to be calculated.

\section{- Source Data}

Source data represents aqueous-phase concentration of chlorinated solvents in the source area. The source term corresponds to a vertical source plume, normal to the direction of ground-water flow, located at the down gradient limit of the area serving as the principal source of solvent release to the ground water. In the absence of such data the point of maximum measured plume concentrations should be considered as the source point. The location of DNAPL can also be identified if aqueous phase concentrations exceed $1 \%$ of solubility. Along the principal direction of groundwater flow, distance to down gradient points of exposure should also be measured from this location.

\subsection{Phase II}

In Phase II, existing biotransformation processes at the site are identified and the major means of solvent degradation is assessed considering U.S.EPA natural attenuation screening protocol.

The U.S.EPA natural attenuation screening protocol assigns a score for each field corresponding to their concentrations. All the scores are added resulting in the final score attained by the site.

The fields, contaminant concentrations, interpretation and score assigned are shown in the Table 1. 
Table 1. Summary of Natural Attenuation Screening Protocol (Source: U.S.EPA, 1998).

\begin{tabular}{|c|c|c|c|}
\hline Field & $\begin{array}{l}\text { Concentrations } \\
\text { in Most } \\
\text { Contaminant } \\
\text { Zone }\end{array}$ & Interpretation & $\begin{array}{l}\text { Score } \\
\text { Assigned }\end{array}$ \\
\hline \multirow[t]{2}{*}{ Oxygen } & $<0.5 \mathrm{mg} / \mathrm{L}$ & $\begin{array}{l}\text { Tolerated, suppresses the reductive } \\
\text { pathway at higher concentration }\end{array}$ & 3 \\
\hline & $>5 \mathrm{mg} / \mathrm{L}$ & $\begin{array}{l}\text { Not tolerated; however, VC may be } \\
\text { oxidized aerobically }\end{array}$ & -3 \\
\hline Nitrate & $<1 \mathrm{mg} / \mathrm{L}$ & $\begin{array}{l}\text { At higher concentrations may } \\
\text { compete with reductive pathway }\end{array}$ & 2 \\
\hline Iron II & $>1 \mathrm{mg} / \mathrm{L}$ & \begin{tabular}{|l|} 
Reductive pathway possible; VC \\
may be oxidized under \\
Fe(III)-reducing conditions \\
\end{tabular} & 3 \\
\hline Sulfate & $<20 \mathrm{mg} / \mathrm{L}$ & $\begin{array}{l}\text { At higher concentrations may } \\
\text { compete with reductive pathway }\end{array}$ & 2 \\
\hline Sulfide & $>1 \mathrm{mg} / \mathrm{L}$ & Reductive pathway possible & 3 \\
\hline Methane & $>0.5 \mathrm{mg} / \mathrm{L}$ & $\begin{array}{l}\text { Ultimate reductive daughter product, } \\
\text { VC Accumulates }\end{array}$ & 3 \\
\hline \multirow{2}{*}{$\begin{array}{l}\text { Oxidation } \\
\text { Reduction Potential } \\
\text { (ORP) }\end{array}$} & $\begin{array}{c}<50 \text { millivolts } \\
(\mathrm{mV})\end{array}$ & Reductive pathway possible & 1 \\
\hline & $<-100 \mathrm{mV}$ & Reductive pathway likely & 2 \\
\hline PH & $5<\mathrm{pH}<9$ & Optimal range for reductive pathway & 0 \\
\hline TOC & $>20 \mathrm{mg} / \mathrm{L}$ & $\begin{array}{l}\text { Carbon and energy source; drives } \\
\text { dechlorination; can be natural or } \\
\text { anthropogenic }\end{array}$ & 2 \\
\hline Temperature & $>20^{\circ} \mathrm{C}$ & $\begin{array}{l}\text { At } \mathrm{T}>20^{\circ} \mathrm{C} \text { biochemical process is } \\
\text { accelerated }\end{array}$ & 1 \\
\hline Carbon Dioxide & $\begin{array}{c}>2 \mathrm{x} \\
\text { background }\end{array}$ & Ultimate oxidative daughter product & 1 \\
\hline Alkalinity & $\begin{array}{c}>2 \mathrm{x} \\
\text { background }\end{array}$ & $\begin{array}{l}\text { Results from interaction of carbon } \\
\text { dioxide with aquifer minerals }\end{array}$ & 1 \\
\hline Chloride & $\begin{array}{c}>2 \mathrm{x} \\
\text { background }\end{array}$ & $\begin{array}{l}\text { Daughter product of organic } \\
\text { chlorine }\end{array}$ & 2 \\
\hline Hydrogen & $>1 \mathrm{nM}$ & $\begin{array}{l}\text { Reductive pathway possible, } \mathrm{VC} \\
\text { may accumulate }\end{array}$ & 3 \\
\hline Volatile Fatty Acids & $>0.1 \mathrm{mg} / \mathrm{L}$ & $\begin{array}{l}\text { Intermediates resulting from } \\
\text { biodegradation of aromatic }\end{array}$ & 2 \\
\hline
\end{tabular}




\begin{tabular}{|l|l|l|c|}
\hline & & $\begin{array}{l}\text { compounds; carbon and energy } \\
\text { source }\end{array}$ & \\
\hline BTEX & $>0.1 \mathrm{mg} / \mathrm{L}$ & $\begin{array}{l}\text { Carbon and energy source; drives } \\
\text { dechlorination }\end{array}$ & 2 \\
\hline PCE & & Material released & 0 \\
\hline TCE & Daughter product of PCE & 2 \\
\hline DCE & $\begin{array}{l}\text { Daughter product of TCE. } \\
\text { If cis is greater than 80\% of total } \\
\text { DCE it is likely a daughter product } \\
\text { of TCE; } 1,1-D C E \text { can be a chem. } \\
\text { reaction product of TCA }\end{array}$ & 2 \\
\hline VC & Daughter product of DCE & 2 \\
\hline $\begin{array}{l}1,1,1- \\
\text { Trichloroethane }\end{array}$ & Material released & 0 \\
\hline DCA & & $\begin{array}{l}\text { Daughter product of TCA under } \\
\text { reducing conditions }\end{array}$ & 2 \\
\hline $\begin{array}{l}\text { Carbon } \\
\text { Tetrachloride }\end{array}$ & Material released & 0 \\
\hline Chloroethane & $>0.01 \mathrm{mg} / \mathrm{L}$ & $\begin{array}{l}\text { Daughter product of DCA or VC } \\
\text { under reducing conditions }\end{array}$ & 2 \\
\hline Ethene/Ethane & $>0.1 \mathrm{mg} / \mathrm{L}$ & Daughter product of VC/ethene & 2 \\
\hline Chloroform & & $\begin{array}{l}\text { Daughter product of Carbon } \\
\text { Tetrachloride }\end{array}$ & 2 \\
\hline Dichloromethane & Daughter product of Chloroform & 2 \\
\hline
\end{tabular}

Depending on the score attained the major means of solvent degradation can be interpreted in to one of the following cases which is shown in Table 2.

Table 2. Score-Interpretation of Chlorinated Organics (Source: U.S.EPA, 1998).

\begin{tabular}{|l|c|l|}
\hline Case & Score & \multicolumn{1}{c|}{ Interpretation } \\
\hline Case I & $0-5$ & $\begin{array}{l}\text { Inadequate evidence for anaerobic } \\
\text { biodegradation of chlorinated organics }\end{array}$ \\
\hline Case II & $6-14$ & $\begin{array}{l}\text { Limited evidence for anaerobic biodegradation } \\
\text { of chlorinated organics }\end{array}$ \\
\hline Case III & $15-20$ & $\begin{array}{l}\text { Adequate evidence for anaerobic } \\
\text { biodegradation of chlorinated organics }\end{array}$ \\
\hline Case IV & $>20$ & $\begin{array}{l}\text { Strong evidence for anaerobic biodegradation of } \\
\text { chlorinated organics }\end{array}$ \\
\hline
\end{tabular}




\subsection{Phase III}

The score attained by the site assists in selection of the appropriate natural attenuation screening model. The selected model is run to the site-specific conditions and, depending on the output from the model, the feasibility of monitored natural attenuation as a remedial option is assessed. 


\section{MODELS}

The groundwater solute fate and transport model is useful for evaluating natural attenuation. Models are useful to predict the migration and degradation of the dissolved contaminant plume and to predict contaminant concentrations in a receptor wells. The selection of model depends on nature of contaminants and major means of solvent degradation.

\section{BIOCHLOR Model}

BIOCHLOR is a screening model developed by the Air Force Center for Environmental Excellence (AFCEE) Technology Transfer Division at Brooks Air Force Base by Groundwater Services, Inc., Houston, Texas, and is used for simulating remediation by natural attenuation (RNA) of dissolved solvents at chlorinated solvent release sites. The Battelle Pacific Northwest National Laboratory researchers developed the mathematical technique that is used to solve the coupled reactive transport equations.

The software programmed in the Microsof̣t Ex cel spreadsheet environment is based on the Domenico analytical solute transport model. It has the ability to simulate 1-D advection, 3-D dispersion, linear adsorption, and biotransformation via reductive dechlorination (the dominant biotransformation process at most chlorinated solvent sites). Under anaerobic conditions reductive dechlorination is assumed to occur, and degradation of dissolved solvent assumed to follow a sequential first-order decay process.

Reductive dechlorination is a microbial-mediated reaction, whereby a chlorine atom on the chlorinated solvent is replaced by a hydrogen atom (Vogel and McCarty, 
1987). In many processes involving bioremediation, organic contaminants like benzene act as electron donors and substances like oxygen or nitrate, etc., act as the electron acceptor. But during reductive dechlorination, hydrogen acts as the electron donor and halogenated compounds, such as chlorinated solvents, act as electron acceptors and thus become reduced. The reduction process is shown in the following half reaction:

$\mathrm{R}-\mathrm{Cl}+\mathrm{H}^{+}+2 \mathrm{e}^{-} \longrightarrow \mathrm{R}-\mathrm{H}+\mathrm{Cl}^{-}$

The reductive transformation pathways for the common chlorinated aliphatic hydrocarbons can be observed in Figure 11. Reductive dechlorination is commonly modeled as a sequential first-order decay process, which implies that a parent compound undergoes first-order decay to produce a daughter product, and that product undergoes first-order decay and so on.

Generally, the more highly chlorinated the compound, the more rapidly it is reduced by reductive dechlorination (Vogel and McCarty, 1985; Vogel and McCarty, 1987). Hence there is a possibility of a rise in concentration of daughter products before actually decreasing as shown in Figure 12.

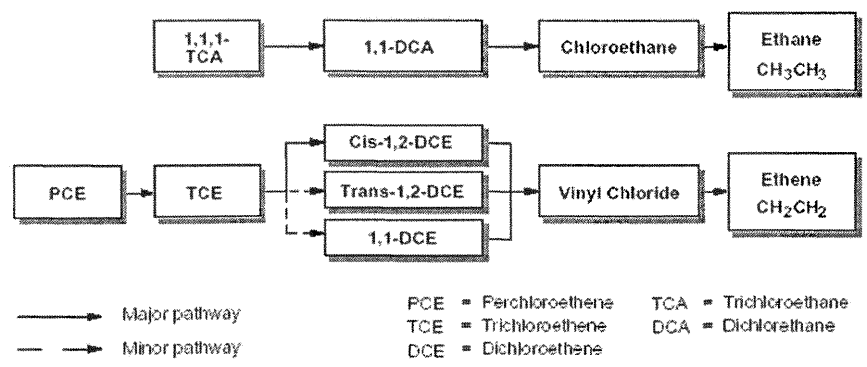

Figure 11. Reductive Dechlorination of Common Aliphatic Hydrocarbons (Source: Aziz et al., 1999). 


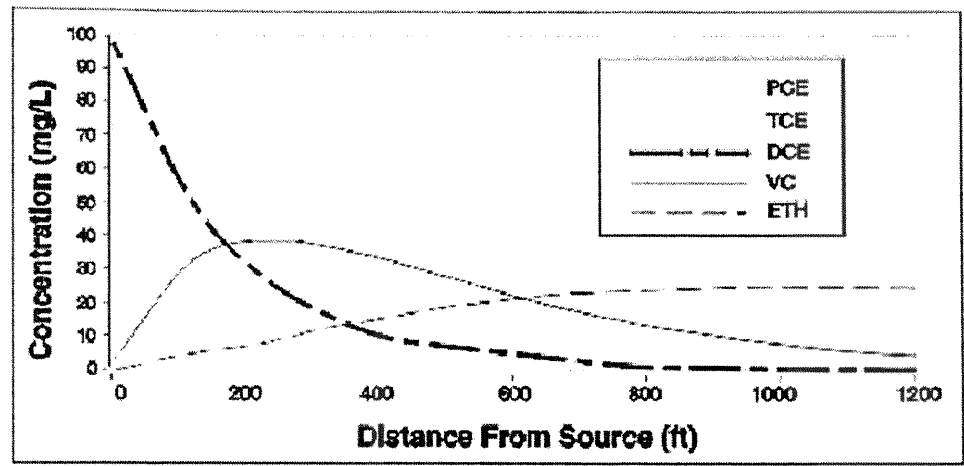

Figure 12. Reductive Transformation of Chlorinated Ethenes (Source: Aziz et al., 1999).

BIOCHLOR incorporates three different model types:

- Solute transport ignoring the decay mechanisms,

- Solute transport assuming sequential first-order decay process as a major means of bioremediation,

- Solute transport assuming sequential first-order decay process as a major means of bioremediation but with two different reaction zones (i.e., each zone has a different set of rate coefficient values).

\section{Role of BIOCHLOR}

The outline of the natural attenuation screening process is shown in Figure 13 and the shaded steps indicate the role of BIOCHLOR in the screening process.

The natural attenuation scoring system comes into play in the first decision box "Is Biodegradation Occurring?" which requires the entry concentrations of electron acceptors, parent and daughter chlorinated solvents, methane, TOC, and chloride and ORP, temperature, and $\mathrm{pH}$ measurements (U.S.EPA, 1998). The field data of these 
components are evaluated and scored for evidence of biotransformation. The scoring system is incorporated in BIOCHLOR, which can be accessed from the input page.

BIOCHLOR is used when there is evidence of contaminant biotransformation to compare the rate of chlorinated solvent transport without biotransformation to the rate of attenuation with biotransformation. As the model is transient (time dependent), the simulation time can be varied to determine the extent of contamination in the future. Field-derived biological rate coefficients are preferred to literature values. The literature values may be used in the absence of site-specific rate constants or the model may be calibrated to field data.

The primary objective of comparing the transport rate to the attenuation rate is to determine if the residence time along the flow path is adequate to protect human health and the environment (i.e., to estimate if the contaminant degrades to an acceptable concentration before receptors are exposed). Sensitivity analyses should be conducted when rate coefficients or any other parameters are not known accurately or that varies over the extent of the plume. If modeling predicts contaminant concentrations below regulatory criteria at the receptors, then the screening criteria are met, and the investigator can proceed with a full natural attenuation evaluation.

Intended use of BIOCHLOR in the Monitored Natural evaluation can be observed in Figure 13. 


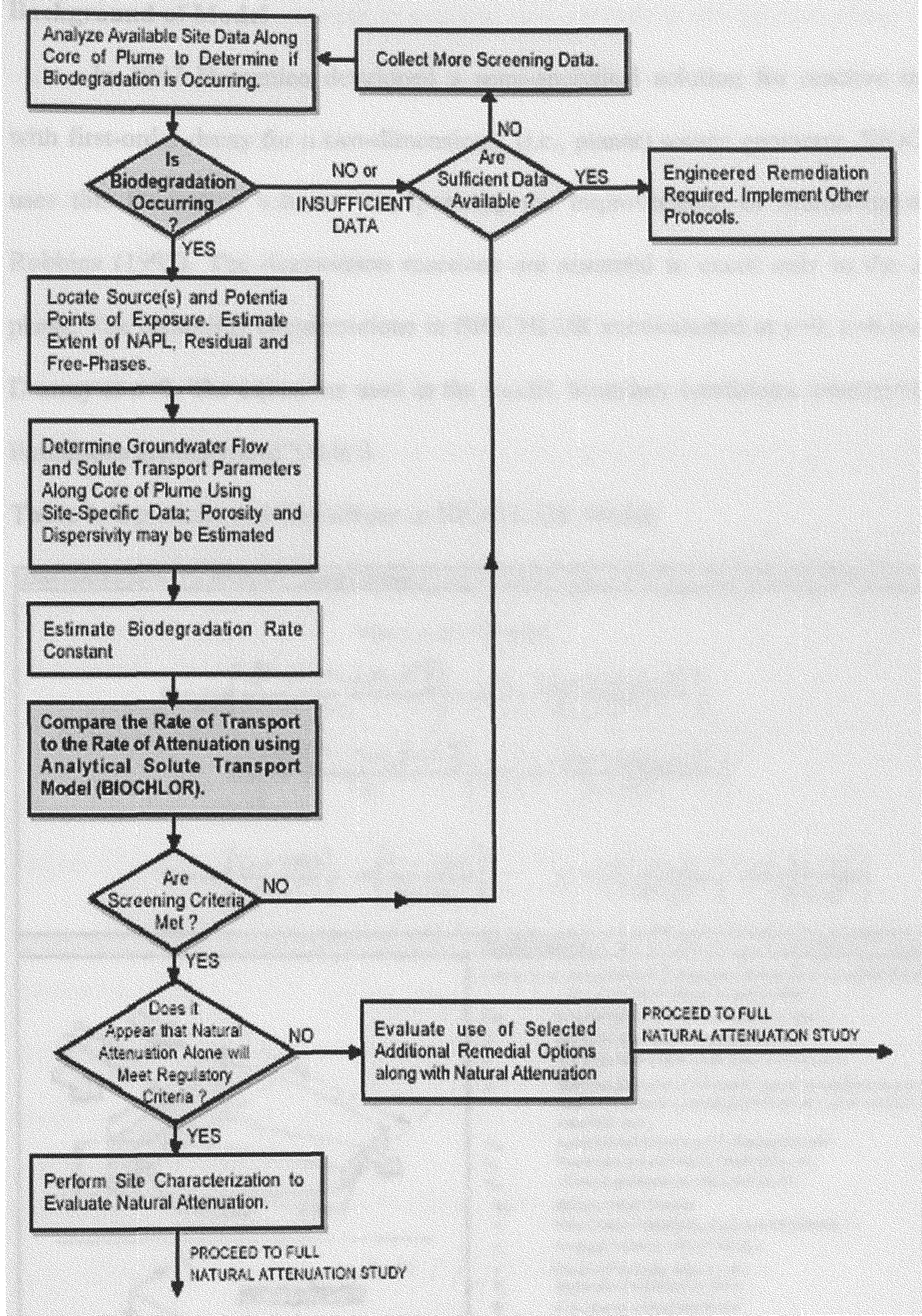

Figure 13. Initial screening process flow chart (Source: U.S.EPA, 1998). 


\section{Background of Model}

In 1987 Domenico developed a semi-analytical solution for reactive transport with first-order decay for a two-dimensional (i.e., planar) source geometry. BIOCHLOR uses this Domenico solution incorporating the improvements of Martin-Hayden and Robbins (1997). The degradation reactions are assumed to occur only in the aqueous phase. The centerline concentrations in BIOCHLOR are evaluated at $y=0, z=0$ and the 2$\mathrm{D}$ array at $\mathrm{z}=0$. The equations used in the model, boundary conditions, assumptions, and limitations are discussed Table 3.

Table 3. Equations and Definitions in BIOCHLOR Model.

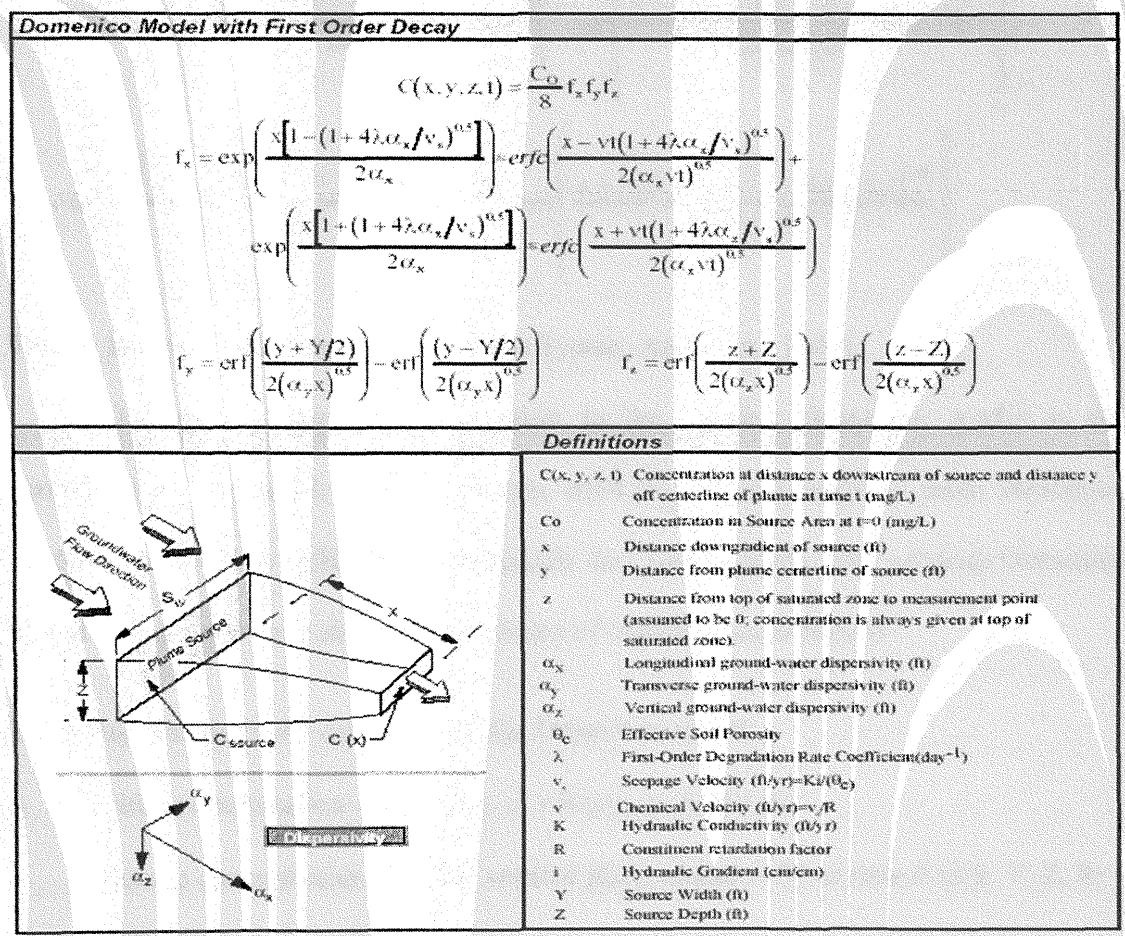


As the biotransformation is assumed to occur only in the aqueous phase, the first order rate constant is divided by $\mathrm{R}$. However use of $\mathrm{R}$ can be substituted by replacing $\mathrm{v}$ (the compound velocity (i.e., vs/R)) in the original Domenico solution with vs, (the seepage velocity).

The Domenico solution was modified to consider chloroethane's (CA) reactive transport in both biotic and abiotic reactions. In reductive dechlorination conditions the first-order rate constant for abiotic decay, A, is added to the biological rate constant, as shown in Figure 14. the remaining terms in the Domenico equation remain the same.

$$
\begin{aligned}
& f_{x}=\operatorname{sen}\left(\frac{x\left[1-\left(1+4\left(\lambda+\lambda_{A} \alpha_{x} \cdot v_{s}\right)^{s .5}\right]\right.}{2 \alpha_{x}}\right) \operatorname{erf}\left(\frac{x-v t\left(1+4\left(\lambda+\lambda_{A} \alpha_{x} \alpha_{s}\right)^{0.5}\right.}{2\left(\alpha_{x} v t\right)^{0.5}}\right)+
\end{aligned}
$$

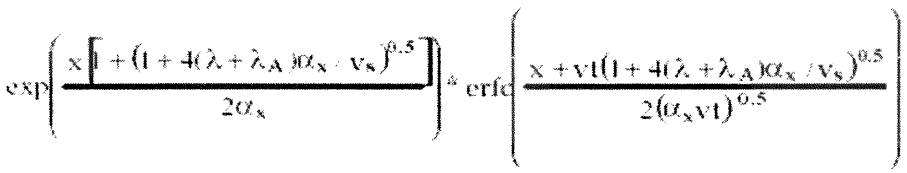

Figure 14. Modified Domenico Solution (Source: Aziz et al., 1999).

One more important modification to the original Domenico model is the simulation of a spatially varying source; BIOCHLOR superimposes three Domenico models, each with a different concentration and source width. The original Domenico model was derived for a single planar source of constant concentration.

Following are the initial conditions of the Domenico model:

- Initial concentration $=0$ for $\mathrm{x}, \mathrm{y}, \mathrm{z},>0(\mathrm{c}(\mathrm{x}, \mathrm{y}, \mathrm{z}, 0)=0)$

- $\quad$ Source concentration for each vertical plane source $=\mathrm{C} 0$ at time $0(\mathrm{c}(0, \mathrm{Y}, \mathrm{Z}, 0)=$ $\mathrm{C} 0)$ 


\section{Chlorinated Ethenes}

The reaction rate equations of the chlorinated ethenes are shown in Figure 15. , the reactions are assumed to undergo the sequential first order decay

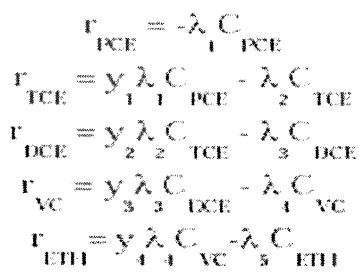

Figure 15. Reaction Rate Equations (Source: Aziz et al., 1999).

Where the subscripts $1,2,3,4$, and 5 to $\lambda$ indicate the first order biotransformation rate coefficients, $y 1, y 2, y 3, y 4$ as the ratios of molecular weights of daughter to parent compounds, and CPCE, CTCE, CDCE, CVC and CETH as the aqueous concentration of PCE, TCE, DCE, vinyl chloride, and ethene, respectively. The above equations clearly show that TCE, DCE, and VC are simultaneously being produced and degraded, which often results in net accumulation before observed degradation. In addition these reaction expressions cause the reactive transport equations to be coupled to each other.

\section{Other Chlorinated Compounds}

Even though BIOCHLOR is designed to model the reductive dechlorination of chlorinated ethenes and ethanes, it can also be used to model any chlorinated compounds, which degrade through sequential first-order decay kinetics. BIOCHLOR can be used for compounds other than chlorinated ethenes and ethanes, but the yield constants (the ratio 
of daughter product to parent compound molecular weights on the input page) have to be specified.

\section{Input to Model}

The input required to run the model is as follows:

\section{Site Specific Data}

- Hydrogeology

- Dispersion

- Adsorption

- Biotransformation

- Source dimensions

\section{General Data}

- Modeling area dimensions

- Simulation time

- Actual data to compare

\section{Output of Model}

The output from the model shows concentrations along the centerline (for two kinetic models at the same time) or as an array (one kinetic model at a time) and all results are for the time entered in the "Simulation Time" box.

\section{- Centerline Output}

Output along centerline is displayed when the "Run Centerline" button is pressed on the input screen. The concentration at the top of the saturated zone $(\mathrm{z}=0)$ along the centerline of the plume $(y=0)$ is displayed in the centerline output screen. The first screen 
shows the concentration profiles and field data for all the constituents on one plot as well as a no-degradation curve for the total chlorinated solvents. This information is plotted on a linear plot. The user may view the output on a semi-log plot by pressing the "Log $\longleftrightarrow \longrightarrow$ Linear" button.

On the second output screen, the user can view the no degradation curves and the biotransformation curves for each constituent, one at a time, by pressing the buttons to the right. The model predictions are also presented in tabular form and may be printed out.

After a simulation has been run and the user has returned to the input page, the user may opt to use the "See Output" button. This button allows the user to go directly to the output without running the model. If the "See Output" button is pressed prior to running a simulation, output errors may result.

\section{- Array Output}

The array output is displayed when the "Run Array" button is pressed on the Input screen. The constituent that is to be viewed is selected from the upper right hand corner and one of the two model types is selected (No Degradation or Biotransformation). A 3-D graphic presents the concentration profile on an 11-point-long by 5-point-wide grid. To alter the modeled area the Model Area Length and Width parameters are adjusted on the input screen.

To see the plume array that exceeds a certain target level (such as an MCL or riskbased cleanup level), the target level is entered in the box and "Plot Data > Target" is pushed. Only sections of the plume exceeding the target level will be displayed. To see 
all the data again "Plot All Data" button has to be pushed. BIOCHLOR automatically resets the button "Plot All Data" when the "Run Array" button is pressed on the input screen. Approximate mass flux data are also presented on the array output screen.

\section{Assumptions}

The key assumptions in the model are listed below. They are:

- The aquifer and flow field are assumed to be homogeneous and isotropic.

- The molecular diffusion in the dispersion terms is ignored by assuming the groundwater velocity as fast, which may not be appropriate for simulation of transport through clays.

- Adsorption is assumed as a reversible process and represented by a linear isotherm.

\section{Limitations}

The key limitations to the model are:

- The model cannot be applied at complicated flow-field systems, which exist during pumping.

- The model cannot be applied at a site where vertical flow gradients affect contaminant transport.

- The model's effectiveness is reduced drastically at sites where hydrogeologic conditions change dramatically. 


\section{RESULTS/DISCUSSIONS}

From Phase I results it is identified that the major contaminants present at the site are PCE (perchloroethene), TCE (trichloroethene), DCE (dichloroethene), VC (vinyl chloride), and ethenes.

The site-specific data used in the model are summarized below

1. Hydrogeology

- $\quad$ Seepage Velocity

- Hydraulic Conductivity

- Hydraulic Gradient

- $\quad$ Effective Porosity
$148.7 \mathrm{ft} / \mathrm{yr}$

$0.023 \mathrm{~cm} / \mathrm{sec}$

$0.025 \mathrm{ft} / \mathrm{ft}$

0.4

2. Dispersion

- $\quad$ Longitudinal Dispersivity $38 \mathrm{ft}$

- $\quad$ Transverse Dispersivity $\quad 3.8 \mathrm{ft}$

- Vertical Dispersivity $\quad 38 \mathrm{E}-99 \mathrm{ft}$

3. Adsorption

- Common Retardation Factor 2.80

- Soil Bulk Density $\quad 1.47 \mathrm{Kg} / \mathrm{L}$

- Fraction Organic Carbon $1.8 \mathrm{E}-3$

- Partition Coefficients(organic carbon- water)

$$
\begin{array}{cc}
\text { PCE } & 426 \mathrm{~L} / \mathrm{Kg} \\
\text { TCE } & 130 \mathrm{~L} / \mathrm{Kg} \\
\text { DCE } & 125 \mathrm{~L} / \mathrm{Kg}
\end{array}
$$




\section{VC $\quad 30 \mathrm{~L} / \mathrm{Kg}$ \\ ETH $302 \mathrm{~L} / \mathrm{Kg}$}

4. Biotransformation

- $\quad \mathrm{PCE} \rightarrow \mathrm{TCE}$

- $\quad$ TCE $\rightarrow$ c-DCE

- $\quad \mathrm{c}-\mathrm{DCE} \rightarrow \mathrm{VC}$

- $\quad \mathrm{VC} \rightarrow \mathrm{ETH}$

5. General

- $\quad$ Modeled Area Width

- Modeled Area Length

6. Source Data

- $\quad$ Source Area
$1.3001 / \mathrm{yr}$

$1.2001 / \mathrm{yr}$

$0.8001 / \mathrm{yr}$

$0.7001 / \mathrm{yr}$
$500 \mathrm{ft}$

$1500 \mathrm{ft}$

\section{Field Data From 1995}

Table 4. 1995 Field Data.

\begin{tabular}{|l|c|c|}
\hline Contaminant & $\begin{array}{l}\text { Concentration in } \mathbf{~ m g / L} \\
\text { at a distance of } \mathbf{0} \mathbf{f t} \text { from } \\
\text { source }\end{array}$ & $\begin{array}{l}\text { Concentration in } \mathbf{~ m g} / \mathbf{L} \\
\text { at a distance of 530 ft } \\
\text { from source }\end{array}$ \\
\hline PCE & 0.064 & - \\
\hline TCE & 7.2 & 3.0 \\
\hline DCE & 9.5 & 12.1 \\
\hline VC & 3.2 & 7.0 \\
\hline ETH & 0.6 & 8.3 \\
\hline
\end{tabular}


In Phase II, the following data is used to identify the major means of solvent degradation at the site:

- Iron II

- Nitrate

- $\mathrm{pH}$

- TOC

- PCE

- TCE

- $\mathrm{VC}$

- Ethene

The score attained by the site is shown in the Table 5 .

Table 5: Site Score.

\begin{tabular}{|l|c|l|c|}
\hline Field & $\begin{array}{l}\text { Concentrations } \\
\text { in Most }\end{array}$ & Interpretation & $\begin{array}{l}\text { Score } \\
\text { Assigned }\end{array}$ \\
\hline Nitrate & $<1 \mathrm{mg} / \mathrm{L}$ & $\begin{array}{l}\text { At higher concentrations may } \\
\text { compete with reductive pathway }\end{array}$ & 2 \\
\hline Iron II & $>1 \mathrm{mg} / \mathrm{L}$ & $\begin{array}{l}\text { Reductive pathway possible; VC } \\
\text { may be oxidized under } \\
\text { Fe(III)-reducing conditions }\end{array}$ & 3 \\
\hline PH & $5<\mathrm{pH}<9$ & $\begin{array}{l}\text { Optimal range for reductive } \\
\text { pathway }\end{array}$ & 0 \\
\hline TOC & $>20 \mathrm{mg} / \mathrm{L}$ & $\begin{array}{l}\text { Carbon and energy source; drives } \\
\text { dechlorination; can be natural or } \\
\text { anthropogenic }\end{array}$ & 2 \\
\hline PCE & & Material released & 0 \\
\hline TCE & $>0.1 \mathrm{mg} / \mathrm{L}$ & Daughter product of PCE & 2 \\
\hline VC & $\begin{array}{l}\text { Daughter product of DCE } \\
\text { Daughter product of VC/ethene }\end{array}$ & 3 \\
\hline Ethene & $\begin{array}{l}\text { Results from interaction of carbon } \\
\text { dioxide with aquifer minerals }\end{array}$ & 1 \\
\hline Alkalinity & \multicolumn{2}{|l}{} \\
\hline Total Score Attained & \multicolumn{2}{|l}{} \\
\hline
\end{tabular}


According to U.S.EPA Natural Attenuation Screening Protocol a score of 15 signifies that there is adequate evidence for anaerobic degradation of chlorinated organics hence BIOCHLOR is selected as a natural attenuation-screening model.

To effectively use the BIOCHLOR model, source area and concentration of contaminants are to be estimated, but as the landfill is around 72 acres in area the whole area cannot be used as the source area because the model cannot accept such large areas as the source areas. To overcome this, a relatively small area is considered representing the same total concentration.

The source is assumed to be of $40 \mathrm{ft}$ in thickness and width of $102 \mathrm{ft}$. Corresponding concentration of the contaminants at this source area are estimated by using the BIOCHLOR model and the concentrations are shown below.

Table 6: Source Concentrations.

\begin{tabular}{|c|c|}
\hline Contaminant & Concentration in $\mathbf{~ m g} / \mathbf{L}$ at source \\
\hline PCE & 5.0 \\
\hline TCE & 202.0 \\
\hline DCE & 150.0 \\
\hline VC & 0.2 \\
\hline ETH & 0.1 \\
\hline
\end{tabular}

As the contaminant concentrations are available only for year 1995 it is appropriate to first estimate the concentrations for year 2002 with in the modeling area. The existing contaminant concentrations are shown below:

- $\quad$ PCE

The PCE concentration and its variance over the modeled area can be observed in Table 7, and Figure 16. 
Table 7. Models Current Estimated PCE Concentrations

\begin{tabular}{|c|c|c|c|c|c|c|c|c|c|c|}
\hline $\begin{array}{c}\text { Transverse } \\
\text { Distance, } \\
\text { feet }\end{array}$ & \multicolumn{2}{|c|}{ Longitudinal Distance From Source, feet } \\
\cline { 2 - 25 } & 0 & 150 & 300 & 450 & 600 & 750 & 900 & 1200 & 1350 & 1500 \\
\hline 200 & 0.000 & 0.000 & 0.000 & 0.000 & 0.000 & 0.000 & 0.000 & 0.000 & 0.000 & 0.000 \\
\hline 100 & 0.000 & 0.001 & 0.001 & 0.001 & 0.000 & 0.000 & 0.000 & 0.000 & 0.000 & 0.000 \\
\hline 0 & 0.028 & 0.013 & 0.005 & 0.002 & 0.001 & 0.001 & 0.000 & 0.000 & 0.000 & 0.000 \\
\hline-100 & 0.000 & 0.001 & 0.001 & 0.001 & 0.000 & 0.000 & 0.000 & 0.000 & 0.000 & 0.000 \\
\hline-200 & 0.000 & 0.000 & 0.000 & 0.000 & 0.000 & 0.000 & 0.000 & 0.000 & 0.000 & 0.000 \\
\hline
\end{tabular}

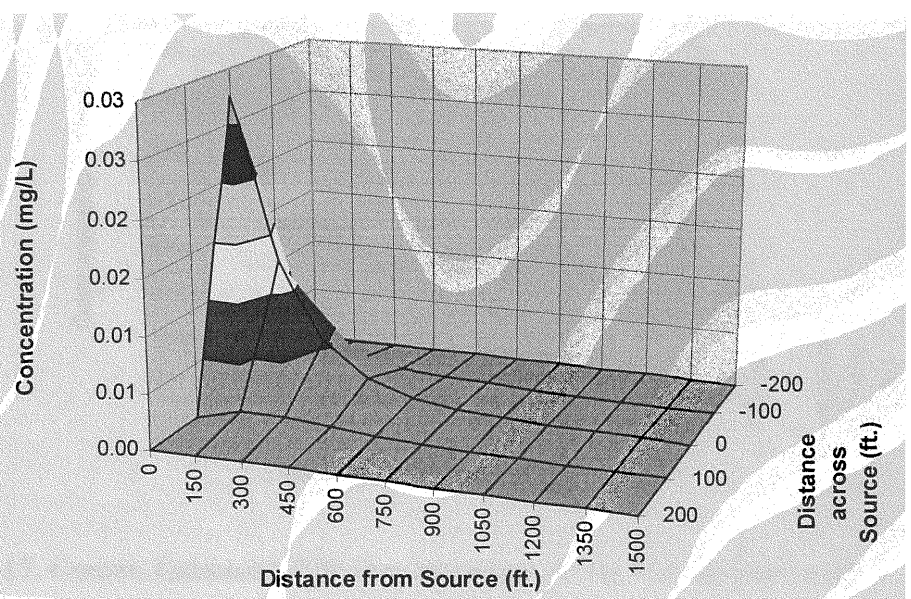

Figure 16. Current Estimated PCE Concentrations Along The Modeled Area.

From the figures and tables it can be observed that the concentration of the PCE is constantly decreasing over the modeled area and becomes zero after around $500 \mathrm{ft}$.

- TCE

The TCE concentration and its variance over the modeled area can be observed in Table 8 and Figure 17. 
Table 8. Models Current Estimated TCE Concentrations.

\begin{tabular}{|c|c|c|c|c|c|c|c|c|c|c|}
\hline $\begin{array}{c}\text { Transverse } \\
\text { Distance, } \\
\text { feet }\end{array}$ & \multicolumn{2}{|c|}{ Longitudinal Distance From Source, feet } \\
\cline { 2 - 25 } & 0 & 150 & 300 & 450 & 600 & 750 & 900 & 1200 & 1350 & 1500 \\
\hline 200 & 0.000 & 0.000 & 0.000 & 0.001 & 0.002 & 0.002 & 0.001 & 0.001 & 0.000 & 0.000 \\
\hline 100 & 0.000 & 0.047 & 0.057 & 0.042 & 0.028 & 0.017 & 0.010 & 0.003 & 0.002 & 0.001 \\
\hline 0 & 1.114 & 0.561 & 0.267 & 0.133 & 0.068 & 0.036 & 0.019 & 0.005 & 0.003 & 0.001 \\
\hline-100 & 0.000 & 0.047 & 0.057 & 0.042 & 0.028 & 0.017 & 0.010 & 0.003 & 0.002 & 0.001 \\
\hline-200 & 0.000 & 0.000 & 0.000 & 0.001 & 0.002 & 0.002 & 0.001 & 0.001 & 0.000 & 0.000 \\
\hline
\end{tabular}

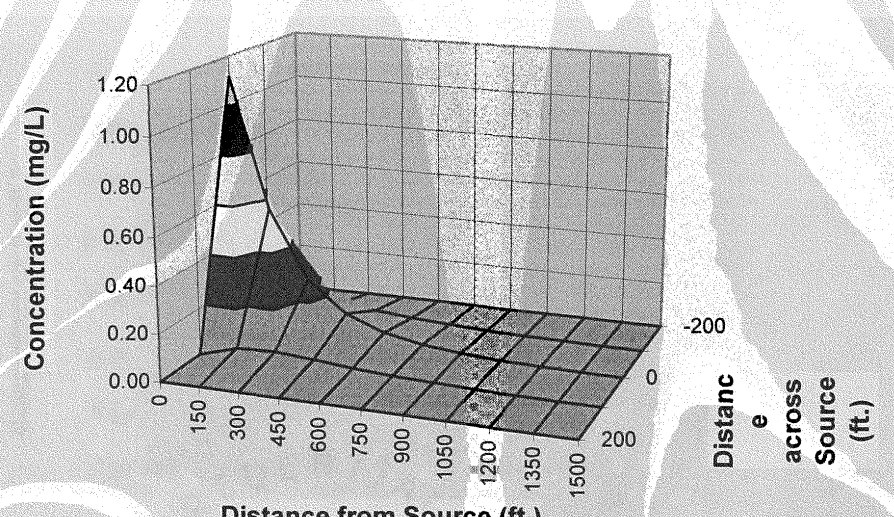

Distance from Source (ft.)

Figure 17. Current Estimated TCE Concentrations Along The Modeled Area.

From the figures and tables it can be observed that the concentration of the TCE is constantly decreasing but not at the same rate as PCE. The concentration of TCE is well above the MCL over almost the whole modeled area and reduces below the limit only around $1200 \mathrm{ft}$ from the source. It can also be observed that the concentration of the contaminants is getting decreasing with vertical distance from the source.

- DCE

The DCE concentration and its variance over the modeled area can be observed in Table 9 and Figure 18. 
Table 9. Models Current Estimated DCE Concentrations.

\begin{tabular}{|c|c|c|c|c|c|c|c|c|c|c|}
\hline $\begin{array}{c}\text { Transverse } \\
\text { Distance, } \\
\text { feet }\end{array}$ & \multicolumn{2}{|c|}{ Longitudinal Distance From Source, feet } \\
\cline { 2 - 28 } & 0 & 150 & 300 & 450 & 600 & 750 & 900 & 1200 & 1350 & 1500 \\
\hline 200 & 0.000 & 0.000 & 0.001 & 0.007 & 0.015 & 0.022 & 0.026 & 0.024 & 0.019 & 0.013 \\
\hline 100 & 0.000 & 0.090 & 0.197 & 0.240 & 0.240 & 0.217 & 0.184 & 0.108 & 0.074 & 0.045 \\
\hline 0 & 0.827 & 1.065 & 0.931 & 0.756 & 0.596 & 0.461 & 0.351 & 0.178 & 0.115 & 0.067 \\
\hline-100 & 0.000 & 0.090 & 0.197 & 0.240 & 0.240 & 0.217 & 0.184 & 0.108 & 0.074 & 0.045 \\
\hline-200 & 0.000 & 0.000 & 0.001 & 0.007 & 0.015 & 0.022 & 0.026 & 0.024 & 0.019 & 0.013 \\
\hline
\end{tabular}

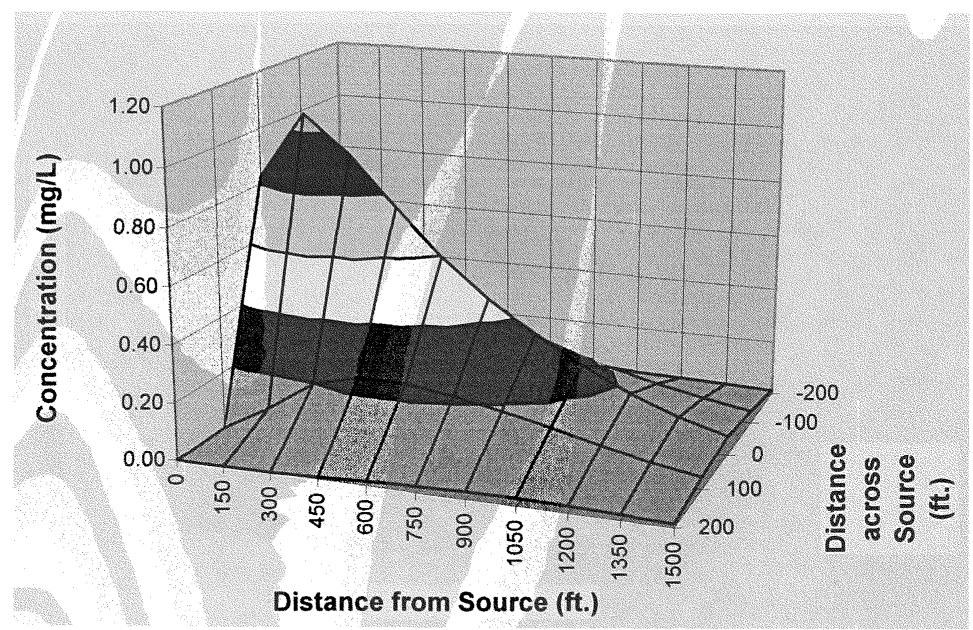

Figure 18. Current Estimated DCE Concentrations Along The Modeled Area.

From the figures and tables it can be observed that the concentration of DCE is decreasing from source center but not at the same rate as TCE. The concentration of DCE is well above the MCL over the whole modeled area. The trend of decrease in the concentration of the contaminants across the source area continues.

\section{- Vinyl Chloride (VC)}

The VC concentration and its variance over the modeled area can be observed in Table 10 and Figure 19. 
Table 10. Models Current Estimated VC Concentrations.

\begin{tabular}{|c|c|c|c|c|c|c|c|c|c|c|}
\hline $\begin{array}{c}\text { Transverse } \\
\text { Distance, } \\
\text { feet }\end{array}$ & \multicolumn{1}{|c|}{ Longitudinal Distance From Source, feet } \\
\cline { 2 - 23 } & 0 & 150 & 300 & 450 & 600 & 750 & 900 & 1200 & 1350 & 1500 \\
\hline 200 & 0.000 & 0.000 & 0.001 & 0.008 & 0.025 & 0.048 & 0.072 & 0.097 & 0.079 & 0.059 \\
\hline 100 & 0.000 & 0.039 & 0.163 & 0.299 & 0.409 & 0.480 & 0.507 & 0.434 & 0.303 & 0.199 \\
\hline 0 & 0.001 & 0.467 & 0.768 & 0.939 & 1.016 & 1.021 & 0.966 & 0.714 & 0.475 & 0.299 \\
\hline-100 & 0.000 & 0.039 & 0.163 & 0.299 & 0.409 & 0.480 & 0.507 & 0.434 & 0.303 & 0.199 \\
\hline-200 & 0.000 & 0.000 & 0.001 & 0.008 & 0.025 & 0.048 & 0.072 & 0.097 & 0.079 & 0.059 \\
\hline
\end{tabular}

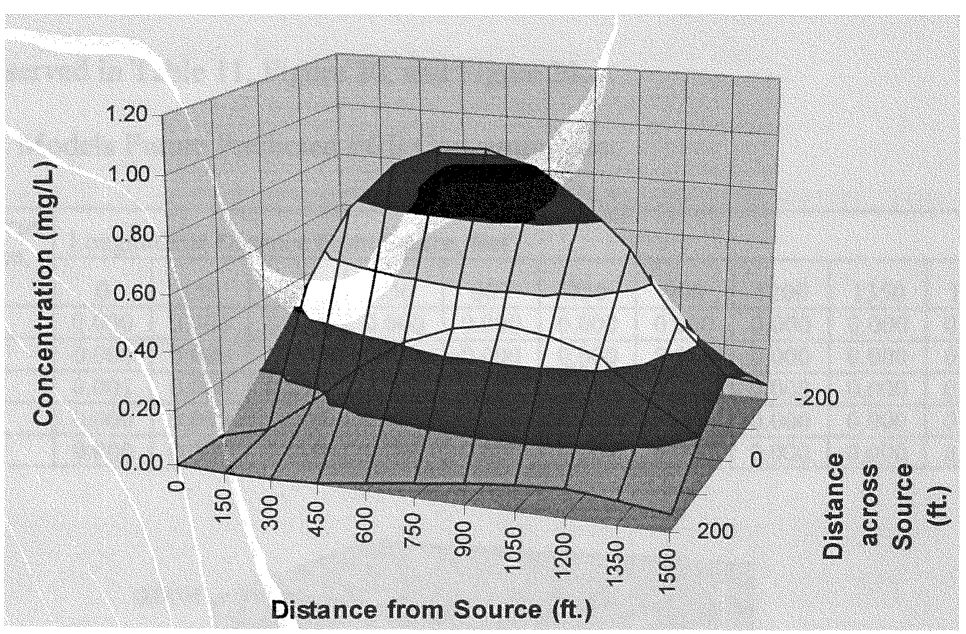

Figure 19. Current Estimated VC Concentrations Along The Modeled Area.

From the figures and tables it can be observed that the concentration of $\mathrm{VC}$ is increasing from the initial concentration, and it is decreasing as we move away from the source center. The concentration of $\mathrm{VC}$ is well above the MCL over the whole modeled area. 
From the above analysis it is clear that the predicted concentration of contaminants by the end of 2002 is well over MCL and that natural attenuation for 26 years will not be sufficient to reduce contaminant concentrations to desired level. An additional 20 more years may be required and the fate of the contaminants through this period is discussed below.

\section{- PCE}

The PCE concentration and its variance at the end of 2022 over the modeled area can be observed in Table 11, Figure 20, and Figure 21.

Table 11. Models Future Predicted PCE Concentrations.

\begin{tabular}{|c|c|c|c|c|c|c|c|c|c|c|}
\hline $\begin{array}{c}\text { Transverse } \\
\text { Distance, } \\
\text { feet }\end{array}$ & \multicolumn{2}{|c|}{ Longitudinal Distance From Source, feet } \\
\cline { 2 - 14 } & 0 & 150 & 300 & 450 & 600 & 750 & 900 & 1200 & 1350 & 1500 \\
\hline 200 & 0.000 & 0.000 & 0.000 & 0.000 & 0.000 & 0.000 & 0.000 & 0.000 & 0.000 & 0.000 \\
\hline 100 & 0.000 & 0.000 & 0.000 & 0.000 & 0.000 & 0.000 & 0.000 & 0.000 & 0.000 & 0.000 \\
\hline 0 & 0.001 & 0.000 & 0.000 & 0.000 & 0.000 & 0.000 & 0.000 & 0.000 & 0.000 & 0.000 \\
\hline-100 & 0.000 & 0.000 & 0.000 & 0.000 & 0.000 & 0.000 & 0.000 & 0.000 & 0.000 & 0.000 \\
\hline-200 & 0.000 & 0.000 & 0.000 & 0.000 & 0.000 & 0.000 & 0.000 & 0.000 & 0.000 & 0.000 \\
\hline
\end{tabular}

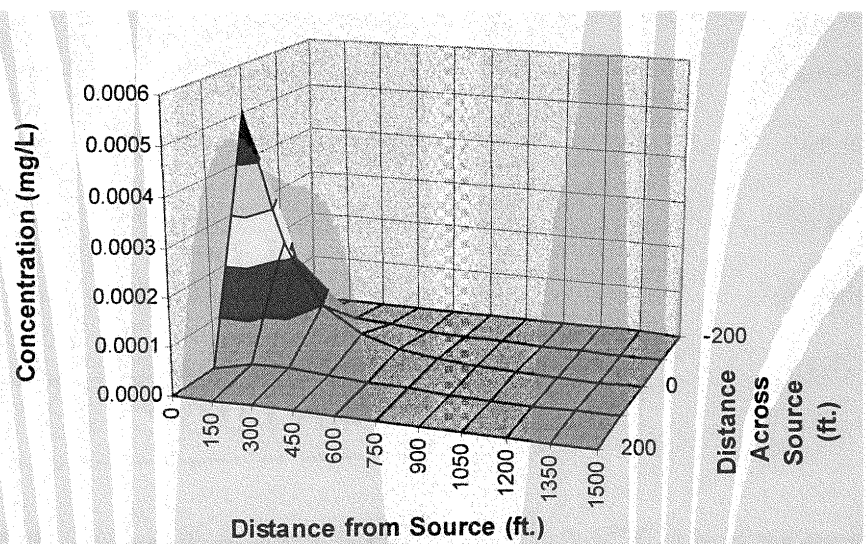

Figure 20. Future Predicted PCE Concentrations Along The Modeled Area. 


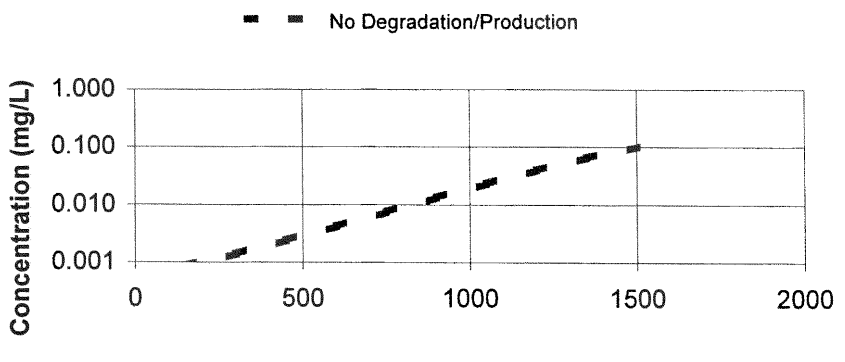

Distance From Source (ft.)

Figure 21. Future Predicted PCE Concentrations Along Center Line.

The PCE concentration is practically zero in the whole modeled area. This is because of reductive chlorination that is PCE is converted in to its daughter products.

\section{Summary of PCE Plume Mass Calculations}

- $\quad$ Plume mass if degradation is absent

- Plume mass due to biotransformation/production $0.0 \mathrm{Kg}$

- $\quad$ Mass removed

- Percent of biotransformation

$+99.9 \%$

- $\quad$ Percent of change in mass rate

$99.8 \%$

- Volume of groundwater in plume

$0.00 \mathrm{MGal}$

- $\quad$ Flow rate of water through surface area

0.005 MGD

- TCE

The TCE concentration and its variance at the end of 2022 over the modeled area can be observed in Table 12, Figure 22, and Figure 23. 
Table 12. Models Future Predicted TCE Concentrations.

\begin{tabular}{|c|c|c|c|c|c|c|c|c|c|c|}
\hline $\begin{array}{c}\text { Transverse } \\
\text { Distance, } \\
\text { feet }\end{array}$ & \multicolumn{2}{|c|}{ Longitudinal Distance From Source, feet } \\
\cline { 2 - 28 } & 0 & 150 & 300 & 450 & 600 & 750 & 900 & 1200 & 1350 & 1500 \\
\hline 200 & 0.000 & 0.000 & 0.000 & 0.000 & 0.000 & 0.000 & 0.000 & 0.000 & 0.000 & 0.000 \\
\hline 100 & 0.000 & 0.001 & 0.001 & 0.001 & 0.001 & 0.000 & 0.000 & 0.000 & 0.000 & 0.000 \\
\hline 0 & 0.020 & 0.010 & 0.005 & 0.002 & 0.001 & 0.001 & 0.000 & 0.000 & 0.000 & 0.000 \\
\hline-100 & 0.000 & 0.001 & 0.001 & 0.001 & 0.001 & 0.000 & 0.000 & 0.000 & 0.000 & 0.000 \\
\hline-200 & 0.000 & 0.000 & 0.000 & 0.000 & 0.000 & 0.000 & 0.000 & 0.000 & 0.000 & 0.000 \\
\hline
\end{tabular}

$=$ No Degradation/Production

$\longrightarrow$ Sequential 1st Order Decay

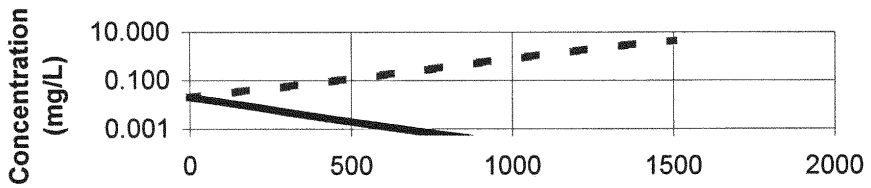

Distance From Source (ft.)

Figure 22. Future Predicted TCE Concentrations Along Centerline.
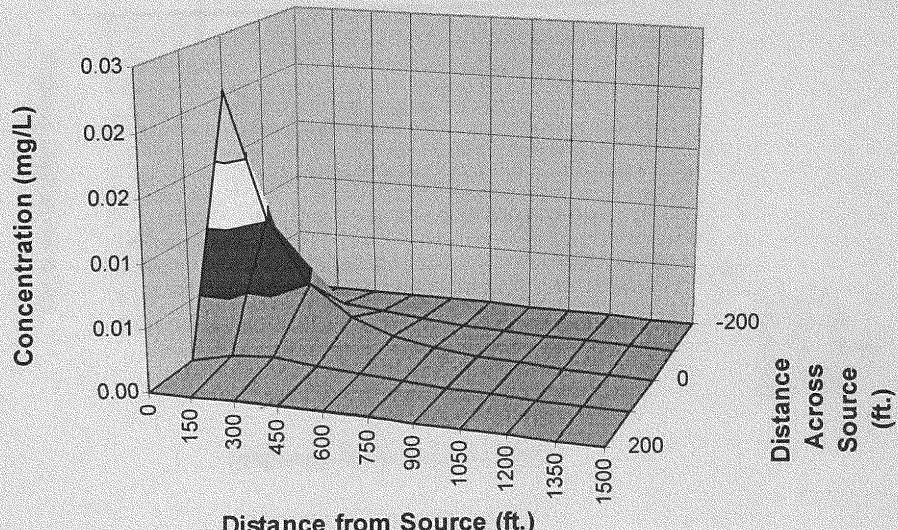

Figure 23. Future Predicted TCE Concentrations Along The Modeled Area. 
The concentration of TCE in the modeled area is well below the MCL (5ppb).

\section{Summary of TCE Plume Mass Calculations}

- $\quad$ Plume mass if degradation is absent

- Plume mass due to biotransformation/production

- Mass removed

- Percent of biotransformation

- Percent of change in mass rate

- Volume of groundwater in plume

- $\quad$ Flow rate of water through surface area
$540.1 \mathrm{Kg}$

$0.7 \mathrm{Kg}$ $539.4 \mathrm{Kg}$

$+99.9 \%$

$99.6 \%$

$3.59 \mathrm{MGal}$

$0.005 \mathrm{MGD}$

\section{- DCE}

The DCE concentration and its variance over the modeled area can be observed in

Table 13, Figure 24, and Figure 25.

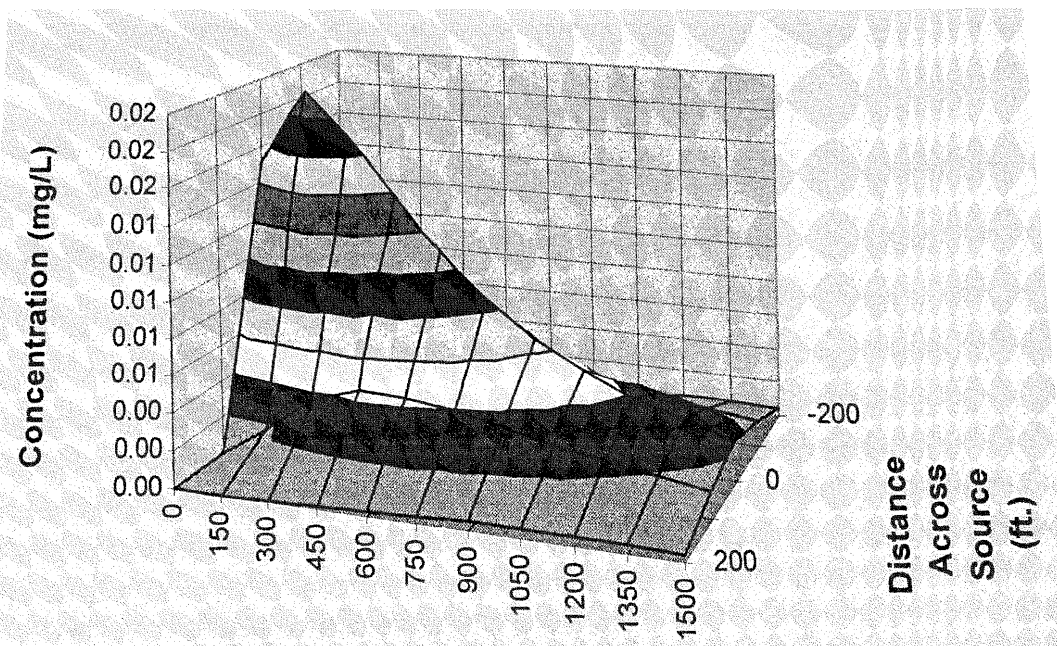

Distance from Source $(\mathrm{ft}$.)

Figure 24. Future Predicted DCE Concentrations Along The Modeled Area. 


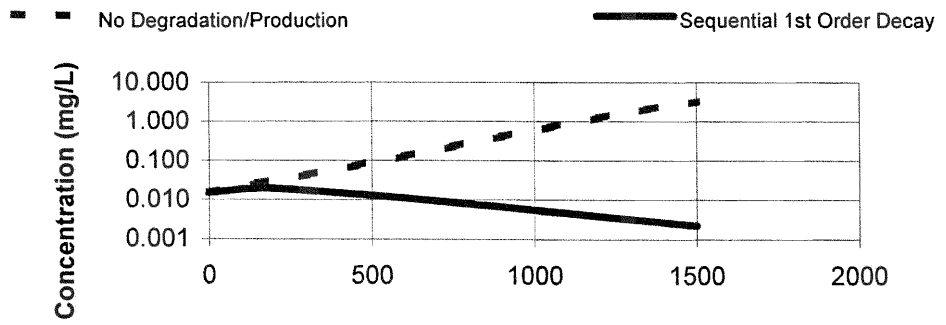

Distance From Source (ft.)

Figure 25. Future Predicted DCE Concentrations Along Centerline.

Table 13. Models Future Predicted DCE Concentrations.

\begin{tabular}{|c|c|c|c|c|c|c|c|c|c|c|}
\hline \multirow{2}{*}{$\begin{array}{c}\text { Transverse } \\
\text { Distance, } \\
\text { feet }\end{array}$} & \multicolumn{10}{|c|}{ Longitudinal Distance From Source, feet } \\
\hline & 0 & 150 & 300 & 450 & 600 & 750 & 900 & 1200 & 1350 & 1500 \\
\hline 200 & 0.000 & 0.000 & 0.000 & 0.000 & 0.000 & 0.000 & 0.000 & 0.001 & 0.000 & 0.000 \\
\hline 100 & 0.000 & 0.002 & 0.004 & 0.004 & 0.004 & 0.004 & 0.003 & 0.002 & 0.002 & 0.002 \\
\hline 0 & 0.015 & 0.020 & 0.017 & 0.014 & 0.011 & 0.008 & 0.007 & 0.004 & 0.003 & 0.002 \\
\hline-100 & 0.000 & 0.002 & 0.004 & 0.004 & 0.004 & 0.004 & 0.003 & 0.002 & 0.002 & 0.002 \\
\hline-200 & 0.000 & 0.000 & 0.000 & 0.000 & 0.000 & 0.000 & 0.000 & 0.001 & 0.000 & 0.000 \\
\hline
\end{tabular}

The concentration of DCE in the modeled area is well below the MCL (5ppb).

\section{Summary of DCE Plume Mass Calculations}

- Plume mass if degradation is absent

- Plume mass due to biotransformation/production

- $\quad$ Mass removed

- Percent of biotransformation

- $\quad$ Percent of change in mass rate

- Volume of groundwater in plume

- $\quad$ Flow rate of water through surface area
$401.1 \mathrm{Kg}$

$3.1 \mathrm{Kg}$

$398.0 \mathrm{Kg}$

$+99.2 \%$

$60.2 \%$

14.36 MGal

0.005 MGD 
- $\quad \mathrm{VC}$

The output for VC in run array mode can be observed in Table 14 and Figure 26 and the centerline output results in Figure 27.

Table 14. Models Future Predicted VC Concentrations.

\begin{tabular}{|c|c|c|c|c|c|c|c|c|c|c|}
\hline $\begin{array}{c}\text { Transverse } \\
\text { Distance, } \\
\text { feet }\end{array}$ & \multicolumn{8}{|c|}{ Longitudinal Distance From Source, feet } \\
\cline { 2 - 26 } & 0 & 150 & 300 & 450 & 600 & 750 & 900 & 1200 & 1350 & 1500 \\
\hline 200 & 0.000 & 0.000 & 0.000 & 0.000 & 0.000 & 0.001 & 0.001 & 0.002 & 0.002 & 0.003 \\
\hline 100 & 0.000 & 0.001 & 0.003 & 0.005 & 0.008 & 0.009 & 0.010 & 0.010 & 0.010 & 0.009 \\
\hline 0 & 0.000 & 0.009 & 0.014 & 0.017 & 0.019 & 0.019 & 0.019 & 0.016 & 0.015 & 0.013 \\
\hline-100 & 0.000 & 0.001 & 0.003 & 0.005 & 0.008 & 0.009 & 0.010 & 0.010 & 0.010 & 0.009 \\
\hline-200 & 0.000 & 0.000 & 0.000 & 0.000 & 0.000 & 0.001 & 0.001 & 0.002 & 0.002 & 0.003 \\
\hline
\end{tabular}

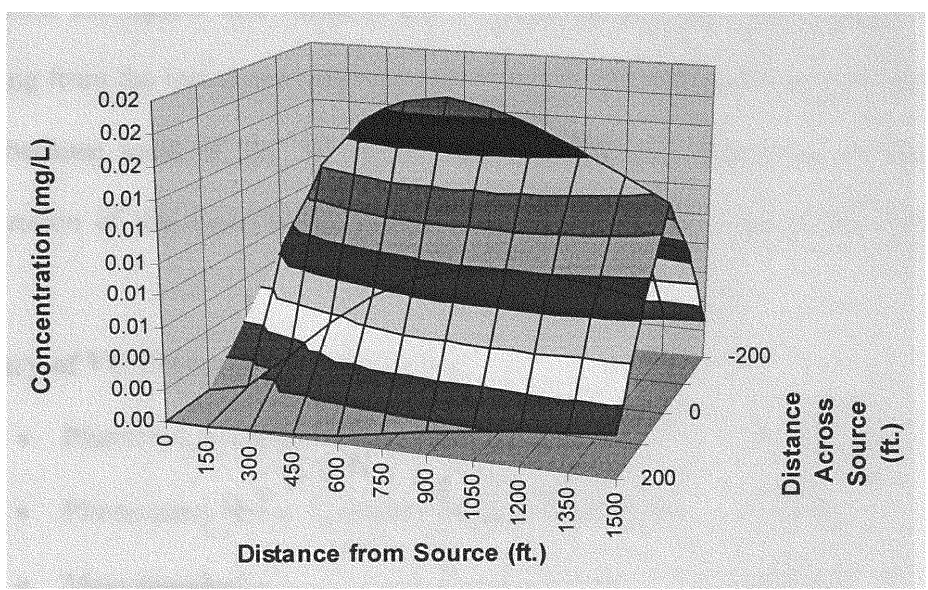

Figure 26. Future Predicted VC Concentrations Along Center Line. 


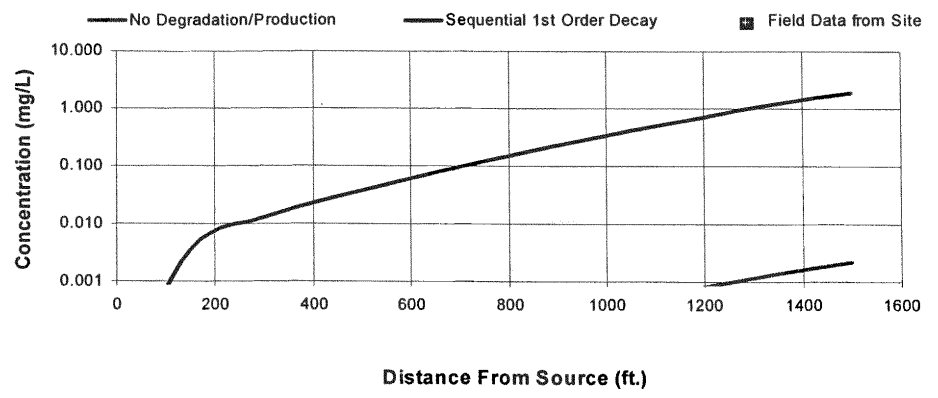

Figure 27. Future Predicted VC Concentrations Along Centerline.

The VC concentrations across the most part of modeled area exceeded MCL $(0.2$ $\mathrm{ppb})$. From the figures and tables it can be observed that the concentration of $\mathrm{VC}$ is increasing from the initial concentration and it is also increasing as we move from source center because most of the VC is converted to Ethenes. The trend in decrease in concentration of the contaminants as we move vertically from the source remains the same.

\section{Summary of VC Plume Mass Calculations}

- Plume mass if degradation is absent

- Plume mass due to biotransformation/production

- Mass removed

- Percent of biotransformation

- Percent of change in mass rate

- Volume of groundwater in plume

- Flow rate of water through surface area
$0.5 \mathrm{Kg}$

$6.3 \mathrm{Kg}$

$-5.8 \mathrm{Kg}$

$-1075.5 \%$

$-178264.2 \%$

* MGal

0.005 MGD

*-- Cannot be calculated. 
The negative sign indicates that there is actually production of contaminant rather than reduction.

\section{- $\quad$ Ethenes}

The Ethenes concentration and its variance over the modeled area can be observed in Table15, Figure 28, and Figure 29.

Table 15. Models Future Predicted Ethenes Concentrations.

\begin{tabular}{|c|c|c|c|c|c|c|c|c|c|c|}
\hline $\begin{array}{c}\text { Transverse } \\
\text { Distance, } \\
\text { feet }\end{array}$ & \multicolumn{8}{|c|}{ Longitudinal Distance From Source, feet } \\
\cline { 2 - 13 } & 0 & 150 & 300 & 450 & 600 & 750 & 900 & 1200 & 1350 & 1500 \\
\hline 200 & 0.000 & 0.000 & 0.001 & 0.013 & 0.073 & 0.234 & 0.538 & 1.328 & 1.488 & 1.338 \\
\hline 100 & 0.000 & 0.016 & 0.141 & 0.489 & 1.186 & 2.314 & 3.774 & 5.958 & 5.724 & 4.538 \\
\hline 0 & 0.001 & 0.190 & 0.664 & 1.538 & 2.947 & 4.921 & 7.188 & 9.809 & 8.957 & 6.814 \\
\hline-100 & 0.000 & 0.016 & 0.141 & 0.489 & 1.186 & 2.314 & 3.774 & 5.958 & 5.724 & 4.538 \\
\hline-200 & 0.000 & 0.000 & 0.001 & 0.013 & 0.073 & 0.234 & 0.538 & 1.328 & 1.488 & 1.338 \\
\hline
\end{tabular}

- No Degradation/Production

Sequential 1st Order Decay

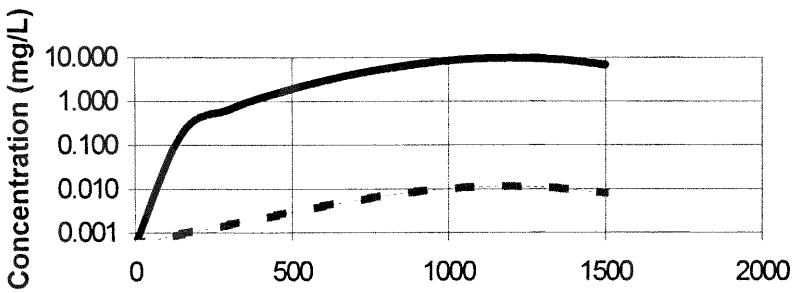

Distance From Source (ft)

Figure 28. Future Predicted Ethenes Concentrations Along The Modeled Area.

The increase in Ethene concentrations is due to subsequent reduction of PCE, TCE, DCE and VC. 


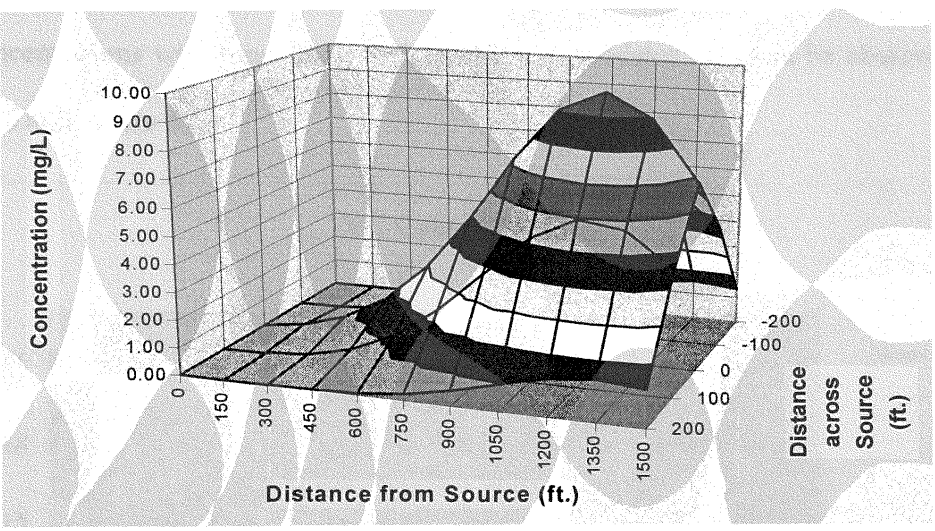

Figure 29. Future Predicted Ethenes Concentrations Along The Modeled Area.

\section{Summary of Ethenes Plume Mass Results}

- Plume mass if degradation is absent

$0.3 \mathrm{Kg}$

- Plume mass due to biotransformation/production

$230.7 \mathrm{Kg}$

- Mass removed

$230.4 \mathrm{Kg}$

- Percent of biotransformation

$-86179.7 \%$

- Percent of change in mass rate

$* \%$

- Volume of groundwater in plume

* MGal

- Flow rate of water through surface area

0.005 MGD

*.- Cannot be calculated. 


\section{VC Concentration Variations}

$\mathrm{VC}$ concentrations with time along the centerline of modeled area can be observed in Table 16 and Figure 30.

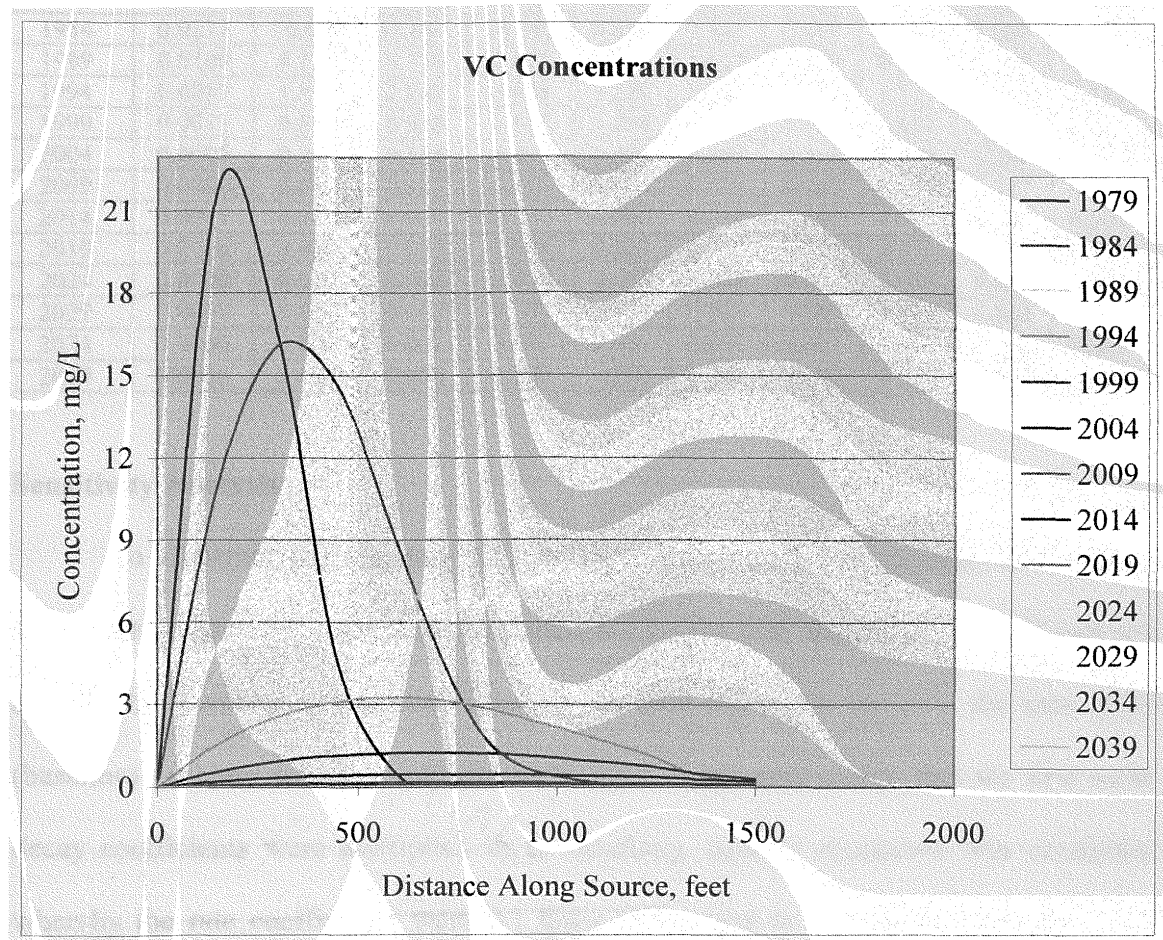

Figure 30. VC Concentrations With Time.

The concentrations are estimated for an interval of 5 years from 1979 to 2039 and it is observed that the maximum concentrations are decreasing with time. 
Table 16. VC Concentrations With Time Period

\begin{tabular}{|c|c|c|c|c|c|c|c|c|c|c|}
\hline \multirow{2}{*}{ Year } & \multicolumn{8}{|c|}{ Concentrations in mg/L Along Longitudinal Distance From Source in feet } \\
\cline { 2 - 12 } & 0 & 150 & 300 & 450 & 600 & 750 & 900 & 1200 & 1350 & 1500 \\
\hline 1979 & 0.0736 & 21.816 & 16.498 & 4.445 & 0.437 & 0.015 & 0.001 & 0.000 & 0.000 & 0.000 \\
\hline 1984 & 0.0271 & 10.989 & 16.064 & 14.582 & 8.814 & 3.435 & 0.833 & 0.007 & 0.000 & 0.000 \\
\hline 1989 & 0.0100 & 4.193 & 6.778 & 7.835 & 7.370 & 5.612 & 3.345 & 0.864 & 0.092 & 0.015 \\
\hline 1994 & 0.0037 & 1.550 & 2.543 & 3.084 & 3.250 & 3.065 & 2.559 & 1.313 & 0.459 & 0.174 \\
\hline 1999 & 0.0013 & 0.570 & 0.938 & 1.147 & 1.238 & 1.239 & 1.160 & 0.811 & 0.511 & 0.303 \\
\hline 2004 & 0.0005 & 0.210 & 0.345 & 0.423 & 0.458 & 0.465 & 0.449 & 0.382 & 0.294 & 0.221 \\
\hline 2009 & 0.0002 & 0.077 & 0.127 & 0.155 & 0.169 & 0.171 & 0.167 & 0.144 & 0.127 & 0.107 \\
\hline 2014 & 0.0001 & 0.028 & 0.047 & 0.057 & 0.062 & 0.063 & 0.062 & 0.054 & 0.049 & 0.043 \\
\hline 2019 & 0.0000 & 0.010 & 0.017 & 0.021 & 0.023 & 0.023 & 0.023 & 0.020 & 0.018 & 0.016 \\
\hline 2024 & 0.0000 & 0.004 & 0.006 & 0.008 & 0.008 & 0.009 & 0.008 & 0.007 & 0.007 & 0.006 \\
\hline 2029 & 0.0000 & 0.001 & 0.002 & 0.003 & 0.003 & 0.003 & 0.003 & 0.003 & 0.002 & 0.002 \\
\hline 2034 & 0.0000 & 0.001 & 0.001 & 0.001 & 0.001 & 0.001 & 0.001 & 0.001 & 0.001 & 0.001 \\
\hline 2039 & 0.0000 & 0.000 & 0.000 & 0.000 & 0.000 & 0.000 & 0.000 & 0.000 & 0.000 & 0.000 \\
\hline
\end{tabular}

\section{Sensitivity Analysis}

To illustrate the response of the BIOCHLOR model to changes in the input parameters, a sensitivity analysis was conducted for the first order decay coefficients and also for the common retardation factor. In the first sensitivity analysis, the case study (baseline) problem was run with the same input parameters except that the first order decay coefficients were multiplied by 2 . Similarly, another simulation was conducted whereby the rate coefficients were 0.1 times those used in the baseline example. The centerline concentrations of PCE, TCE and the daughter products $450 \mathrm{ft}$ downgradient from the source are shown in Table 16 for each simulation. In this instance, the simulated concentrations of PCE and its daughter products increase substantially when the rate coefficient is decreased by a factor of ten and doubling the rate coefficient decreases the chlorinated solvent concentrations. It is observed that the chlorinated ethene concentrations are very sensitive to the magnitude of the rate coefficient. 
Table 17. Sensitivity Analysis Results - Rate Coefficients.

\begin{tabular}{|c|c|c|c|}
\hline Constituent & \multicolumn{3}{|c|}{ Concentrations, (mg/l) } \\
\hline & 2X Base line test & Base line test & 0.1X Base line test \\
\hline PCE & 0.000 & 0.000 & 0.001 \\
\hline TCE & 0.000 & 0.002 & 0.059 \\
\hline DCE & 0.002 & 0.014 & 0.074 \\
\hline VC & 0.005 & 0.017 & 0.015 \\
\hline
\end{tabular}

In contrast, changes in the retardation factor have nominal effects on the dissolved chlorinated solvent concentrations as shown in Table 17. In this sample case, when the retardation factor is decreased from the baseline value of 2.8 , chlorinated solvent concentrations increase slightly. Also, with an increase in the retardation factor chlorinated solvent concentrations in the modeled area decrease by a small amount.

Table 18. Sensitivity Analysis Results -Retardation factor.

\begin{tabular}{|c|c|c|c|}
\hline Constituent & \multicolumn{3}{|c|}{ Concentrations, (mg/l) } \\
\hline & $\mathbf{R}=\mathbf{1 . 0}$ & $\mathbf{R}=\mathbf{2 . 8}$ & $\mathbf{R = 4}$ \\
\hline PCE & 0.000 & 0.000 & 0.000 \\
\hline TCE & 0.001 & 0.002 & 0.004 \\
\hline DCE & 0.005 & 0.014 & 0.029 \\
\hline VC & 0.006 & 0.017 & 0.041 \\
\hline
\end{tabular}




\section{CONCLUSION}

In this study the concentrations of primary contaminants and their daughter products are estimated over the entire modeled area for the modeled period of time using the BIOCHLOR model. The analysis of results revealed that natural attenuation alone is capable of reducing the PCE, TCE and DCE concentrations well below the MCL but VC concentration is exceeding that limit. Table 18 summarizes the plume mass results due to natural attenuation.

Table 19. Plume Mass Calculations.

\begin{tabular}{|c|c|c|}
\hline Contaminant & Plume Mass Removed, Kg & Percent of Biotransformation \\
\hline PCE & 12.5 & $99.9 \%$ \\
\hline TCE & 539.4 & $99.9 \%$ \\
\hline DCE & 398.0 & $99.2 \%$ \\
\hline VC & -5.8 & $-1075.5 \%$ \\
\hline
\end{tabular}

The negative symbol in the above table signifies the excess in production of contaminants compared to degradation.

The results of study also indicate that the concentrations of VC becomes below MCL only after 2034, which is more than the assigned period of time. Of all the contaminants VC is a confirmed carcinogen hence its concentration above MCL is the least preferred. If the site demands earlier cleanup compared to 2034, natural attenuation should be used in conjunction with other treatment technologies. VC concentrations can be reduced if biodegradation rates are increased; with the increase in degradation rates the quantity of $\mathrm{VC}$ converting to ethenes and subsequently to carbon dioxide and water 
increases (Haston, et.al., 1994). The degradation process in general is inhibited by the availability of oxygen and nutrients. Hence injection of oxygen and nutrients would be a potential remedial technology that can be used along with MNA.

From the sensitivity analysis that was performed on the model to observe its sensitivity to input parameters it was concluded that resulting chlorinated ethene concentrations indicate a greater sensitivity to decay coefficients than to retardation factors. As the accuracy of this procedure mainly depends on degradation rates, therefore laboratory studies are needed to be conducted for the site-specific conditions.

The procedure that is followed in this study can be used at any of the sites contaminated with chlorinated solvents and with small adjustments it can be extended to the sites contaminated from petroleum hydrocarbons.

One of the limiting factors in this approach is an assumption of homogeneity for geologic and hydrogeologic conditions that may not always be true. 


\section{REFERENCES}

1. Aziz, C.E., Newell, C.J., Gonzales, A.R., Haas, P., Clement, T.P., and Sun, Y., 1999, BIOCHLOR NATURAL attenuation Decision Support System User's Manual, Prepared for the Air Force Center for Environmental Excellence, Brooks AFB, San Antonio, TX.

2. Bear, J., 1972, Dynamics of Fluids in Porous Media, Dover Publications, New York, pp. 569.

3. Bear, J., 1979, Hydraulics of groundwater, New York, NY: McGraw-Hill.

4. Commission on Intrinsic Remediation, 2000, Natural attenuation for groundwater remediation, National Academy Press, pp. 229.

5. De Bruin, W.P., Kotterman, M.J.J., Posthumus, M.A., Schraa, G., and, Zehnder, A.J.B., 1992, Complete biological reductive transformation of tetrachloroehthene to ethane, Appl. Environ, Microbiol, 58(6): 1966-2000.

6. Domenico, P.A., 1987, An analytical model for multidimensional transport of a decaying contaminant species, J. Hydrol., 91:49-58.

7. Environmental Restoration, Predictive Modeling, Retrieved September 05,2002 from, http://www.afcee.brooks.af.mil/er/ert/predict.htm.

8. Freeze, R.A., and Cherry, J.A., 1979,Groundwater: Englewood Cliffs, NJ, Prentice Hall, Inc., 604 p.

9. FRTR, 2002a, Remediation Technologies Screening Matrix and Reference Guide, Version 4.0, In Situ Physical/Chemical Treatment, Passive/Reactive Treatment Walls, Retrieved September 02, 2002 from, http://www.frtr.gov/matrix $2 /$ section4/4-41.html.

10. FRTR, 2002b, Remediation Technologies Screening Matrix and Reference Guide, Version 4.0, In Situ Physical/Chemical Treatment, Thermal Treatment, Retrieved August 10, 2002 from, http://www.frtr.gov/matrix $2 /$ section4/4-38.html.

11. FRTR, 2002c,Remediation Technologies Screening Matrix and Reference Guide, Version 4.0, In Situ Physical/Chemical Treatment, Hydrofracturing, Retrieved September 02, 2002 from, http://www.frtr.gov/matrix2/section4/439.html

12. FRTR, 2002d, Remediation Technologies Screening Matrix and Reference Guide, Version 4.0, In Situ Physical/Chemical Treatment, Air Sparging, 
Retrieved August 20, 2002 from, http://www.frtr.gov/matrix2/section4/434.html.

13. FRTR, 2002e, Remediation Technologies Screening Matrix and Reference Guide, Version 4.0, In Situ Physical/Chemical Treatment, In Well Air Stripping, Retrieved September 02, 2002 from, http://www.frtr.gov/matrix $2 /$ section4/4-40.html.

14. FRTR, 2001, Remediation Technologies Screening Matrix and Reference Guide, Version 4.0, In Situ Physical/Chemical Treatment, Directional Wells, Retrieved August 20, 2002 from, http:/www.frtr.gov/matrix2/section4/436.html.

15. GWRTAC, Ground-Water Remediation Technologies Analysis Center, Technical Documents-Technical Status Reports, Retrieved August 05,2002 from, http://www.gwrtac.org/html/tech_status.html.

16. Groundwater Services, Inc., 1998, Remediation by natural attenuation (RNA) tool kit. User's Manual, Houston, TX.

17. Guidance on Developing a Monitored Natural Attenuation Remedial Proposal for Chlorinated Organics in Ground Water, 2000, Draft http://wastenot.enr.state.nc.us/hwhome/guidance/pdf/MNA-GID.FIN.pdf

18. Haston, Z.C., P.K. Sharma, J.N. Black, and P.L. McCarty. , 1994, Enhanced reductive dechlorination of chlorinated ethenes, In: U.S.EPA Symposium on Bioremediation of Hazardous Wastes: Research, Development, and Field Evaluation, EPA/600/R-94/075. Washington, DC, pp. 11-14.

19. Hazen, T.C., 1996, Case study: full-scale in situ bioremediation demonstration (methane biostimulation) of the Savannah River Site integrated demonstration project, Westinghouse Savannah River Company publication number WSRC-TR-96-0044, Aiken, South Carolina.

20. Hazen, T.C., K.H. Lombard, B.B. Looney, M.V. Enzien, J.M. Dougherty, C.B. Fliermans, J. Wear, and C.A. Eddy-Dilek., 1994, Summary of in-situ bioremediation demonstration (methane biostimulation) via horizontal wells at the Savannah River Site integrated demonstration project, (pgs. 137-150), In: In-Situ Remediation: Scientific Basis for Current and Future Technologies. Battelle Press, Columbus, Ohio.

21. In Situ Bioremediation Using Horizontal Wells, Innovative Technology Summary Report, 1995, Retrieved August 10,2002 from, http://www.em.doe.gov/plumesfa/intech/isbuhw/index.html. 
22. McAllister, P.M. and C.Y.Chiang ., 1994, A practical approach to evaluating natural attenuation of contaminants in groundwater, Groundwater Monitoring and Remediation, pp.161-173.

23. McCarty, P.L., and L. Semprini., 1994, Ground-water treatment for chlorinated solvents, Norris, R.D., ed. Handbook of bioremediation. Boca Raton, FL: Lewis Publishers, pp. 87-116.

24. Monitored Natural Attenuation: Is It Appropriate? When and Where? Retrieved August 10,2002 from, http://www.cpeo.org/pubs/fsnalw.html, Last Updated August 30,1998.

25. National Research Council, 1994, Alternatives for ground water cleanup, Washington, DC.

26. National Research Council, 1993, In situ bioremediation, When does it work? Washington, DC: National Academy Press, pp.207.

27. Newell, C.J., Rifai, H.S., Wiedemeir, T.H., and Wilson, J.T., 1999, Natural Attenuation of Fuels and Chlorinated Solvents in the Subsurface, John Wiley \& Sons, Inc.

28. Potential for Bioremediation of Groundwater Contaminated with Landfill Leachate, 2001, Retrieved September 05,2002 from, http://www.srs.gov/general/pubs/fulltext/ms2001228/ms2001228.html.

29. Randall C., Groundwater Hydraulics and Pollutant Transport, Prentice hall, 2000.

30. Remediation Technologies Development Forum, 1997, Natural attenuation of chlorinated solvents in groundwater, class notes, RTDF.

31. Sandia Natural Attenuation Project, Natural Attenuation, Retrieved July 16,2002 from, http://www.sandia.gov/eesector/gs/gc/snap.html, Last Updated November 15, 2000.

32. Sandia Report, 1999, Site Screening and Technical Guidance for Monitored Natural Attenuation at DOE Sites.

33. Spitz, K., and Moreno, J., 1996, A Practical Guide to Groundwater and Solute Transport Modeling, Wiley, New York, pp. 461.

34. United States Department of Energy, 2001, Sanitary Landfill Groundwater Monitoring Report, Retrieved November 25,2002 from http://www.srs.gov/general/pubs/fulltext/tr2002049/tr2002049.pdf. 
35. U.S. Environmental Protection Agency, A Citizen Guide to Natural Attenuation, Retrieved August 10,2002 from, http://www.cluin.org/products/citguide/natural.htm, Last Updated October 15,1996.

36. USEPA, 2000, BIOCHLOR natural attenuation decision support system (user's manual), Office of Research and Development, pp. 46.

37. USEPA, 1999, Draft EPA Region 4 suggested practices for evaluation of a site for natural attenuation (biological degradation) of chlorinated solvents, U. S. EPA Region 4, pp. 40.

38. USEPA, 2001, Evaluation of The Protocol for Natural Attenuation of Chlorinated Solvents, Case Study at The Twin Cities Army Ammunition Plant, Retrieved July 03,2002 from, http://www.epa.gov/ada/download/reports/epa_600_r01_025.pdf

39. U.S. Environmental Protection Agency, 1994, Innovative Treatment Technologies: Annual Status Report, Sixth Edition

40. U.S. Environmental Protection Agency, 1993, Remediation Technologies Screening Matrix and Reference Guide, Version I.

41. U.S. Environmental Protection Agency, 1994, Superfund Innovative Technology Evaluation Program, Technologies Profiles. Seventh Edition.

42. USEPA, 1998, Technical Protocol for Evaluating Natural Attenuation of Chlorinated Solvents in Groundwater, Retrieved September 10,2002 from, http://www.epa.gov/oerrpage/superfund/resources/gwdocs/prointro.pdf.

43. Viessman, W., Lewis, G.L., and Knapp, J.W., 1989, Introduction to Hydrology, 3 rd ed., HarperCollins, New York.

44. Vogel, T.M., and P.L. McCarty., 1985, Biotransformation of tetrachloroethylene to trichloroethylene, dichloroethylene, vinyl chloride, and carbon dioxide under methanogenic conditions, Appl, Environ, Microbiol, 49(5): 1080-1083.

45. Vogel, T.M., and P.L. McCarty., 1987, Abiotic and Biotic Transformations of 1,1,1-Trichloroethane under Methanogenic Conditions, Environ. Sci. Technol., 21(12): 1208-1213.

46. Vogel, T.M., 1994, Natural bioremediation of chlorinated solvents, Handbook of Bioremediation, Lewis Publishers, Boca Raton, FL.

47. Walton, W.C., 1991, Principles of Groundwater Engineering. Lewis Publishers, Boca Raton, FL, pp. 546. 
48. Westinghouse Savannah River Site Scientific \& Technical Information, Full Text Document Collection, Retrieved September 28,2002 from, http://www.srs.gov/general/pubs/fulltext/fulltext.htm, Last Updated January 27,2003 .

49. Wiedemeier, T. H., Swanson, M.A., Mountoux, D.E., Gordon, E.K., Wilson, J.T., Wilson, B.H., Kampbell, D.H., Hansen, J.E., Haas, P., and Chapelle, F.H., 1996, Technical protocol for evaluating natural attenuation of chlorinated solvents in groundwater, Air Force Center for Environmental Excellence, San Antonio, Texas.

50. Wilson, J.T., J.W. Weaver, and D.H. Kampbell., 1994, Intrinsic Bioremediation of TCE in ground water at NPL site in ST. Joseph, Michigan, In: U.S. EPA Sympsoium on Intrinsic Bioremidiation of Ground Water, Denver, CO, August 30-September 1. EPA/540/R-94/515, pp. 154160. 


\section{APPENDIX}

Fortran Code Used in BIOCHLOR.

Modeling Coupled PCE, TCE, DCE, VC and ETH Transport and Degradation in

C 3-Dimensional Ground-water Aquifers

C This Fortran code was developed by: T.P. Clement \& Y. Sun

C Battelle Pacific Northwest National Laboratory.

$\operatorname{PARAMETER}(\mathrm{nx}=60, \mathrm{ny}=31, \mathrm{nc}=5)$

c ny should always be an odd number

$\mathrm{REAL} * 4 \mathrm{k}$

DIMENSION c(nx,ny,nc),a(nx,ny,nc),k(nc),y(nc),c0(nc),a0(nc)

c Input data for Martin-Hayden and Robbins test problem

c Reference: Vol 35(2), p.339, Groundwater,1997.

$\mathrm{dx}=20.0$ !delta $\mathrm{x}$

$\mathrm{dy}=20.0$ !delta $\mathrm{y}$

$t=33.0$ !total simulation time (years)

reta $=5.3$ !effective retardation factor

$\mathrm{v}=111.7 /$ reta !velocity $(\mathrm{ft} / \mathrm{yr})$

$\mathrm{ax}=16.4$ !alpha $\mathrm{x}(\mathrm{ft})$

ay $=1.64$ !alpha y (ft)

$\mathrm{az}=0.0$ !alpha $\mathrm{z}$

xsdim $=0.0$ !source dimensions

ysdim $=100.0$ 
$\operatorname{zsdim}=10.0$

c Automatically set source locations

xsloc $=0.0$ !source $\mathrm{x}$ location is fixed at the left boundary

ysloc $=((($ ny-1)/2)+1)*dy !fix source y location at the grid center

c Input reaction parameters

$k(1)=2.0 /$ reta !effective pce decay rate $(1 / \mathrm{yr})$

$\mathrm{k}(2)=1.5 /$ reta $!$ tce decay rate

$k(3)=0.8 /$ reta $!$ dce decay rate

$k(4)=0.65 /$ reta $! \mathrm{vc}$ decay rate

$k(5)=0.000000001$ !ethene decay rate

$y(1)=0.79492 !$ ytce/pce

$y(2)=0.73744 !$ ydce/tce

$y(3)=0.64499 ! \mathrm{yvc} / \mathrm{dce}$

$y(4)=0.4496 !$ yeth/vc

c Input source concentrations

$\mathrm{c} 0(1)=0.1 ! \mathrm{mg} / 1$ source concentration for pce

$\operatorname{co}(2)=15.8$ !for tce

$\mathrm{c} 0(3)=98.5$ !for dce

$\mathrm{c} 0(4)=3.1$ !for vc

$\mathrm{c} 0(5)=0.03$ !for eth

c Computing transformation coefficients

$$
\begin{aligned}
& \mathrm{p} 21=\mathrm{y}(1)^{*} \mathrm{k}(1) /(\mathrm{k}(1)-\mathrm{k}(2)) \\
& \mathrm{p} 32=\mathrm{y}(2)^{*} \mathrm{k}(2) /(\mathrm{k}(2)-\mathrm{k}(3))
\end{aligned}
$$


$\mathrm{p} 31=\mathrm{y}(1)^{*} \mathrm{y}(2) * \mathrm{k}(1) * \mathrm{k}(2) /((\mathrm{k}(1)-\mathrm{k}(3)) *(\mathrm{k}(2)-\mathrm{k}(3)))$

$\mathrm{p} 43=\mathrm{y}(3) * \mathrm{k}(3) /(\mathrm{k}(3)-\mathrm{k}(4))$

$\mathrm{p} 42=\mathrm{y}(2)^{*} \mathrm{y}(3)^{*} \mathrm{k}(2) * \mathrm{k}(3) /((\mathrm{k}(2)-\mathrm{k}(4)) *(\mathrm{k}(3)-\mathrm{k}(4)))$

$\mathrm{p} 41=\mathrm{y}(1) * \mathrm{y}(2) * \mathrm{y}(3) * \mathrm{k}(1) * \mathrm{k}(2) * \mathrm{k}(3) /$

$\$((\mathrm{k}(1)-\mathrm{k}(4)) *(\mathrm{k}(2)-\mathrm{k}(4)) *(\mathrm{k}(3)-\mathrm{k}(4)))$

$\mathrm{p} 54=\mathrm{y}(4) * \mathrm{k}(4) /(\mathrm{k}(4)-\mathrm{k}(5))$

$\mathrm{p} 53=\mathrm{y}(3)^{*} \mathrm{y}(4)^{*} \mathrm{k}(3)^{*} \mathrm{k}(4) /((\mathrm{k}(3)-\mathrm{k}(5)) *(\mathrm{k}(4)-\mathrm{k}(5)))$

$\mathrm{p} 52=\mathrm{y}(2) * \mathrm{y}(3) * \mathrm{y}(4) * \mathrm{k}(2) * \mathrm{k}(3) * \mathrm{k}(4) /$

$\$((\mathrm{k}(2)-\mathrm{k}(5)) *(\mathrm{k}(3)-\mathrm{k}(5)) *(\mathrm{k}(4)-\mathrm{k}(5)))$

$\mathrm{p} 51=\mathrm{y}(1)^{*} \mathrm{y}(2) * \mathrm{y}(3)^{*} \mathrm{y}(4) * \mathrm{k}(1) * \mathrm{k}(2) * \mathrm{k}(3) * \mathrm{k}(4) /$

$\$((\mathrm{k}(1)-\mathrm{k}(5)) *(\mathrm{k}(2)-\mathrm{k}(5)) *(\mathrm{k}(3)-\mathrm{k}(5)) *(\mathrm{k}(4)-\mathrm{k}(5)))$

c Initial concentration is assumed to be zero for all species

c Transform all boundary conditions into "a" domain

$\mathrm{a} 0(1)=\mathrm{c} 0(1)$

$\mathrm{a} 0(2)=\mathrm{c} 0(2)+\mathrm{p} 21 * \mathrm{c} 0(1)$

$\mathrm{a} 0(3)=\mathrm{c} 0(3)+\mathrm{p} 32 * \mathrm{c} 0(2)+\mathrm{p} 31 * \mathrm{c} 0(1)$

$\mathrm{a} 0(4)=\mathrm{c} 0(4)+\mathrm{p} 43 * \mathrm{c} 0(3)+\mathrm{p} 42 * \mathrm{c} 0(2)+\mathrm{p} 41 * \mathrm{c} 0(1)$

$\mathrm{a} 0(5)=\mathrm{c} 0(5)+\mathrm{p} 54 * \mathrm{c} 0(4)+\mathrm{p} 53 * \mathrm{c} 0(3)+\mathrm{p} 52 * \mathrm{c} 0(2)+\mathrm{p} 51 * \mathrm{c} 0(1)$

c Solve the problem using Domenico solution in the "a" domain

DO ic $=1, \mathrm{nc}$

CALL Domenico(nx,ny,dx,dy,t,xloc,ysloc,xsdim,ysdim,zsdim,v,

$\$$ ax,ay,az,a0(ic),k(ic),a(1,1,ic)) 


\section{END DO}

c Transforming back into the "c" domain

c Transform Species \#1

DO iy=1, ny

DO ix $=1, \mathrm{nx}$

$c(i x, i y, 1)=a(i x, i y, 1)$

END DO

END DO

C Transform Species \#2

DO iy=1,ny

DO ix=1,nx

$c(i x, i y, 2)=a(i x, i y, 2)-p 21 * c(i x, i y, 1)$

END DO

END DO

c Transform Species \#3

DO iy=1,ny

DO ix $=1, \mathrm{nx}$

$c(i x, i y, 3)=a(i x, i y, 3)-p 32 * c(i x, i y, 2)-p 31 * c(i x, i y, 1)$

END DO

END DO

c Transform Species \#4

DO iy $=1$, ny

DO ix $=1, n x$ 
$\mathrm{c}(\mathrm{ix}, \mathrm{iy}, 4)=\mathrm{a}(\mathrm{ix}, \mathrm{iy}, 4)-\mathrm{p} 43 * \mathrm{c}(\mathrm{ix}, \mathrm{iy}, 3)$

$\$-$ p $42 *$ c(ix,iy,2) - p $41 *$ c(ix,iy, 1)

END DO

END DO

c Transform Species \#5

DO iy=1,ny

DO ix=1,nx

$c(i x, i y, 5)=a(i x, i y, 5)-p 54 * c(i x, i y, 4)$

$\$-$ p53*c(ix,iy,3) - p52*c(ix,iy,2) - p51*c(ix,iy,1)

END DO

END DO

c Output concentration array

OPEN(10,FILE="conc.out",FORM='FORMATTED',STATUS='UNKNOWN')

$\mathrm{DO}$ ic $=1, \mathrm{nc}$

Write $\left(10,{ }^{*}\right)$ "Species\# =",ic

DO $\mathrm{i}=1$, ny

WRITE $(10,12)(\mathrm{c}(\mathrm{j}, \mathrm{i}, \mathrm{ic}), \mathrm{j}=1, \mathrm{nx})$

\section{ENDDO}

\section{ENDDO}

12 FORMAT (10e15.6)

c Ouput centerline concentrations

OPEN(12,FILE="center.out",FORM='FORMATTED',STATUS='UNKNOWN') $\mathrm{i}=((($ ny-1)/2)+1) !center line location 
DO $\mathrm{j}=1, \mathrm{nx}$

WRITE $(12,14) \mathrm{j}^{*} \mathrm{dx},(\mathrm{c}(\mathrm{j}, \mathrm{i}, \mathrm{ic}), \mathrm{ic}=1,5)$

END DO

14 FORMAT(F10.2,5e15.5)

STOP

END

SUBROUTINE Domenico(nx,ny,dx,dy,t,xsloc,ysloc,xsdim,ysdim,

\$ zsdim,v,ax,ay,az,c0,k,c)

USE MSIMSL ! using IMSL subroutine

REAL*4 k

DIMENSION c(nx,ny)

DO $j=1$, ny

DO $\mathrm{i}=1, \mathrm{nx}$

$c(i, j)=0.0$

ENDDO

ENDDO

c Domenico Anlytical Solution is used as in Martin-Hayden and Robbins paper

c See equations 5 \& 1 in GW vol.35(2), 1997, pages p.345 and 340.

$\mathrm{cc}=\operatorname{SQRT}\left(1 .+\left(4 .{ }^{*} \mathrm{k}^{*} \mathrm{ax} / \mathrm{v}\right)\right)$

DO $\mathbf{j}=1$, ny

DO $\mathrm{i}=1, \mathrm{nx}$

$\mathrm{x}=\mathrm{i} * \mathrm{dx}-\mathrm{x}$ sloc

$y=j^{*} d y-y s l o c$ 
$\mathrm{z}=0.0$ !at the water table

$\mathrm{h} \times 2=\operatorname{ERFC}\left(\left(\mathrm{x}-\mathrm{v}^{*} \mathrm{t} * \mathrm{cc}\right) /\left(2 * \operatorname{SQRT}\left(a x^{*} \mathrm{v}^{*} \mathrm{t}\right)\right)\right)$

IF (hx2 .LE. 1.0e-30) THEN

$\mathrm{h} 1=0.0$

\section{ELSE}

$\mathrm{hx} 1=\operatorname{EXP}\left(\left(\mathrm{x}^{*}(1 .-\mathrm{cc})\right) /\left(2 .^{*} \mathrm{ax}\right)\right)$

$\mathrm{h} 1=\mathrm{hx} 1 * \mathrm{hx} 2$

END IF

$\mathrm{hx} 4=\operatorname{ERFC}\left((\mathrm{x}+\mathrm{v} * \mathrm{t} * \mathrm{cc}) /\left(2 * \operatorname{SQRT}\left(a x^{*} \mathrm{v}^{*} \mathrm{t}\right)\right)\right)$

IF (hx4 .LE. 1.0e-30) THEN

$\mathrm{h} 2=0.0$

\section{ELSE}

$\mathrm{hx} 3=\operatorname{EXP}\left(\left(\mathrm{x}^{*}(1 .+\mathrm{cc})\right) /\left(2 \cdot{ }^{*} \mathrm{ax}\right)\right)$

$\mathrm{h} 2=\mathrm{h} \times 3 * \mathrm{hx} 4$

END IF

$h x=h 1+h 2$

$\mathrm{fy}=\operatorname{ERF}\left((\mathrm{y}+\mathrm{ysdim} / 2.0) /\left(2.0 * \operatorname{SQRT}\left(\operatorname{ay}^{*} \mathrm{x}\right)\right)\right)$

\$-ERF $\left((y-y s d i m / 2.0) /\left(2.0 * \operatorname{SQRT}\left(a{ }^{*} x\right)\right)\right)$

IF (az. LE .1.0e-30) THEN

$\mathrm{fz}=2.0$

ELSE

$\mathrm{fz}=\operatorname{ERF}\left((\mathrm{z}+\mathrm{zsdim}) /\left(2.0^{*} \operatorname{SQRT}\left(\mathrm{az}^{*} \mathrm{x}\right)\right)\right)$

$\$-\operatorname{ERF}\left((z-z s d i m) /\left(2.0 * \operatorname{SQRT}\left(a z^{*} x\right)\right)\right)$ 


\section{ENDIF}

$c(i, j)=(c 0 / 8.0) * h x^{*} f y * f z$

END DO

END DO

RETURN

END 